\title{
Composición y predictores sociodemográficos de los consumidores de noticias
}

\section{Sociodemographic profiles and predictors of news consumers}

Juan Pablo Artero. Universidad de Zaragoza. España.

jpartero@unizar.es

$[\underline{\mathrm{CV}}]$ (1) $\mathrm{G}$

Víctor Orive. Universidad de Zaragoza. España.

orive@,unizar.es

$[\mathrm{CV}]$ (8)

Pilar Latorre. Universidad de Zaragoza. España.

latorrep@unizar.es

$[\underline{\mathrm{CV}}] \bigcirc \mathrm{G}$

Cómo citar este artículo / Referencia normalizada

Artero, J. P., Orive, V. y Latorre, P. (2020). Composición y predictores sociodemográficos de los consumidores de noticias. Revista Latina de Comunicación Social, (77), 55-72. https://www.doi.org/10.4185/RLCS-2020-1449

\section{RESUMEN}

Introducción: La presente investigación tiene como propósito conocer la composición sociodemográfica de los consumidores de noticias en España en la última década. Metodología: A partir de diez encuestas aplicadas por el Centro de Investigaciones Sociológicas (CIS) entre 2006 y 2017 con muestras de entre 2.455 y 3.191 personas, se buscó determinar si los perfiles sociodemográficos de consumo de medios son distintos entre sí y si predicen eficientemente el consumo. Resultados: Se concluye que Internet ha aumentado los niveles de consumo de los diarios impresos y digitales. El consumo de noticias en radio y televisión están tan generalizado que las variables sociodemográficas elegidas no permiten establecer diferencias apreciables. Sin embargo, los lectores de periódicos son más masculinos, más urbanos, de edades intermedias, de clases medias y altas y con mayor nivel formativo que la media de la población. Los usuarios de noticias en Internet coinciden básicamente con el perfil anterior excepto en la edad, ya que su público es más joven que la media. En el caso de los periódicos e Internet, las variables que predicen su consumo más eficientemente son el nivel de estudios y el sexo femenino (en negativo) y la clase social (en positivo). Por último, los coeficientes de correlación entre el consumo de noticias en los tres medios son significativos, aunque no muy altos.

PALABRAS CLAVE: competencia; intermedios; consumo de noticias; predictores sociodemográficos.

\begin{abstract}
Introduction: This research article examines the sociodemographic profile of Spanish news consumers in the last decade. Methods: The study is based on ten surveys conducted by the Centre for Sociological Research (CIS, according to its initials in Spanish) between 2006 and 2017, on
\end{abstract}


samples ranging from 2,455 to 3,191 participants, to determine whether sociodemographic profiles of news consumers are different across media platforms and whether they can efficiently predict news consumption. Results: It is concluded that the Internet has increased the consumption of print and digital newspapers. News consumption in radio and television is so widespread that the selected sociodemographic variables do not allow us to detect noticeable differences. However, newspaper readers are predominantly male, urban, middle-aged, middle and upper class, and highly educated. Internet news consumers basically match the previous profile, except in terms of age, as they are younger. In the case of newspaper and Internet news, the variables that predict their consumption more efficiently are education level, female sex (negative correlation) and social class (positive correlation). Finally, the correlation coefficients between news consumption in all three media platforms are significant, but not very high.

KEYWORDS: competition; news media; news consumption; sociodemographic predictors.

\section{CONTENIDOS}

1. Introducción. 2. Método. 3. Resultados. 3.1. Frecuencias de consumo de noticias. 3.2. Perfil sociodemográfico de los consumidores de noticias. 3.3. Predictores del consumo de noticias. 3.4. Correlaciones entre el consumo de noticias en diferentes medios. 4. Discusión. 5. Conclusiones. 6. Referencias.

Traducción de C. A. Martínez-Arcos (PhD, Universidad de Londres)

\section{Introducción}

En los últimos años se ha extendido la preocupación en profesionales y sociales sobre el modo en que la sociedad se informa a través de los medios de comunicación. Según una visión bastante extendida, la generalización de Internet como medio informativo habría devenido en una disminución del interés por la información en medios tradicionales tales como los diarios, la radio y la televisión. A su vez, en medios académicos, una corriente cada vez más extendida explicaría esta disminución del consumo de noticias por factores no tanto sociodemográficos sino más bien de intereses personales y estilo de vida. Estos hechos provocaría efectos negativos sobre el sistema democrático al conformar una ciudadanía menos y peor informada.

Desde ese contexto, el propósito de esta investigación es conocer la composición sociodemográfica de los consumidores de noticias en España en la última década. Por ello sus objetivos se centran en describir estadísticamente las frecuencias de consumo de los diferentes medios, así como su perfil sociodemográfico y los posibles predictores del consumo de noticias, especialmente los debidos a factores estructurales, como los clásicos de edad, sexo, hábitat, clase social y nivel de instrucción. El problema de investigación reside en la dificultad de contar con datos significativos con los que poder describir e inferir una realidad tan amplia como el consumo de noticias. Además, las investigaciones tienden a fijarse en un medio concreto o en grupos de edad específicos, lo que dificulta las visiones de conjunto. Finalmente, la consolidación de la web como medio de comunicación ha planteado retos conceptuales y metodológicos difíciles de obviar.

Inicialmente, puede decirse el consumo de noticias en Internet no difiere drásticamente del de los medios tradicionales. Sin embargo, la investigación suele mostrar tres limitaciones: la premisa de la división entre medios impresos, audiovisuales y digitales; la noción de que el análisis debe tratar las características de los medios y las prácticas sociales separadamente; y la inclinación a enfocarse en patrones de fenómenos ordinarios o extraordinarios, pero no en los dos a la vez (Mitchelstein y Boczkowski, 2010). A la hora de comprender cómo las audiencias se interesan por el periodismo en 
nuestros días, se debe concebir el consumo mediático no sólo como algo que hacemos, sino como algo que hacemos en un lugar en concreto. El periodismo ahora se produce para facilitar lugares de consumo cada vez más móviles (Espacio); para ajustarse al ritmo más rápido de la era de la información (Velocidad); y para interactuar con y proveer múltiples canales de acceso para las audiencias (Conveniencia) (Peters, 2012).

Además, los dispositivos móviles han causado un cambio paradigmático en la accesibilidad y el consumo de noticias en la vida diaria. La mayor parte de la investigación contemporánea se ha basado en cuatro áreas temáticas: patrones, personas, lugares y participación (Westlund, 2015). Paralelamente, el consumo digital en el lugar de trabajo revela algunas discontinuidades con respecto al de noticias impresas y audiovisuales. Por ejemplo, la relevancia de las nociones de rutina, espacio, tiempo y sociabilidad. Pero también es necesario renovar la comprensión de cómo esos conceptos cambian cuando el medio cambia de tradicional a digital y las prácticas de consumo coinciden con las del trabajo (Boczkowski, 2010).

Lejos de haber perdido su importancia, los medios tradicionales como periódicos y televisiones han emergido como los más importantes proveedores de noticias locales digitales (Waldman et al., 2011). En Estados Unidos se han cerrado 1.800 periódicos locales desde 2004. Pero otros medios como las televisiones y los emprendedores digitales han hecho esfuerzos para llenar el vacío que queda cuando un periódico local muere (Abernathy, 2018), algo que también ha ocurrido en España (Manfredi, Rojas y Herranz de la Casa, 2015). El Estudio General de Medios (2018) revela que los diarios impresos han disminuido su penetración social en los últimos veinte años desde el 36 al 22 por ciento. La radio ha aumentado del 53 al 57 por ciento. Y la televisión ha bajado del 89 al 85 por ciento. Estos datos por sí solos serían demoledores si no fuera porque Internet ha pasado de apenas el 2 al 77 por ciento de penetración en el mismo periodo 1998-2018. Aunque no todos los usuarios por día consumen contenidos informativos, bien podría suponerse que las pérdidas de audiencia de los medios tradicionales podrían haberse compensado con los aumentos de Internet.

Según algunas contribuciones recientes, la mayoría de los ciudadanos todavía recurren a los medios tradicionales para mantenerse informados, aunque lo suplementan con servicios en línea en circunstancia específicas. Aun así muestran una tendencia clara a las marcas en las que confían. Pero esas noticias en dispositivos móviles se están infiltrando progresivamente en las vidas diarias de audiencias que habían desconectado de la información (Van Damme et al., 2015). Puede decirse que las plataformas tradicionales y digitales proporcionan las mismas gratificaciones. De hecho el consumo de noticias multimedia no disminuye el de los medios tradicionales. Más todavía, algunas investigaciones señalan que el consumo de televisión refuerza el de noticias digitales y viceversa. Lo que confirma que las audiencias, en este estudio las jóvenes, usan complementariamente los antiguos y nuevos medios (Van Cauwenberge, d'Haenens y Beentjes, 2010)

Según la literatura, aquellos que en el pasado consumían noticias en periódicos o televisión se dividen ahora entre múltiples plataformas. Alternativamente, los miembros de la audiencia pueden cambiar su atención hacia medios digitales o huir de las noticias a la vez. Aunque hay que reconocer el valor de analizar patrones de consumo específicos de un medio, no hay modo de medir el consumo total de noticias si el consumo individual en distintos medios no puede ser agregado. De hecho algunos segmentos de población acceden a múltiples fuentes de información. La mayoría de los lectores de Internet son usuarios multicanal, leen el periódico y ven las noticias televisivas. Los internautas interesados en las noticias son más tendentes a consumir información también en otros medios que aquellos no interesados en la información. De hecho, no hay evidencia de declive en el consumo de noticias desde la llegada de Internet, de modo que el consumo informativo total incluso aumenta (Ksiazek, Malthouse y Webster, 2010). 
Algunos autores sostienen que el comportamiento de los consumidores de medios no es muy diferente en términos demográficos o socioeconómicos (Pentina y Tarafdar, 2014). Pero por otro lado, el consumo de noticias de pago está relacionado con variables predictoras como la edad, los ingresos, la compra de otros productos digitales y el uso de redes sociales. Del mismo modo, aquellos que ya pagan por noticias impresas son más susceptibles de pagar por noticias digitales en el futuro. La intención de pago también depende de otros factores personales, como la percepción de valor, el interés informativo y los patrones de consumo general (Goyanes, Artero y Zapata, 2018).

Las gratificaciones de vigilancia y evasión son predictores consistentes del consumo informativo. Sin embargo, la fortaleza del hábito es el predictor más poderoso en general. El consumo de periódicos locales se relaciona fuertemente con el conocimiento de los temas de actualidad (Diddi y LaRose, 2006). El consumo de noticias parece depender pues más de la categoría informativa, el género del lector y el interés en un tema particular que en si se ofrece en impreso o digital. De hecho, los lectores digitales no consumen ni retienen la información de manera diferente a los de versiones impresas (D'Haenens, Jankowski y Heuvelman, 2004). Algunos factores como el nivel del ingresos, la densidad de población de la zona o el nivel de minorías no afectarían a la robustez de la oferta informativa (Napoli et al., 2018).

Al seleccionar sus fuentes de información, los ciudadanos eligen aquellas que sostienen posiciones ideológicas similares a las suyas (Chan y Suen, 2008). Los ciudadanos desean consumir noticias que son consistentes con sus gustos o creencias previas. Sin embargo ese hecho no necesariamente daña a los ciudadanos más conscientes, ya que son más capaces de recopilar información de múltiples medios a medida que estos son más sesgados (Xiang y Sarvary, 2007). Las redes sociales aumentan esta relación con medios similares al propio enfoque, ya que proveen información relevante que es filtrada por personas que piensan de modo parecido. Sin embargo también exponen a fuentes no verificadas, anónimas y más subjetivas (Pentina y Tarafdar, 2014). En general el consumo mediático estimula la participación cívica y política. Por ejemplo, en mercados estadounidenses donde existe la televisión en español, la participación electoral de los hispanos aumenta entre 5 y 10 puntos porcentuales (Obeholzer-Gee y Waldfogel, 2006). En general, los factores demográficos y políticosociales cuentan para determinar la participación electoral. Pero también los hábitos de consumo mediático lo hacen, como escuchar la radio y estar interesado en las noticias (Livingstone y Markham, 2008).

Dado que los jóvenes adultos son usuarios más intensivos de Internet, los efectos de su preferencia por los medios digitales son más fuertes para ellos que para otras personas más mayores (Bachmann et al, 2010). Entre los jóvenes, es más patente la emergencia de las redes sociales como un medio informativo y el declive de los medios tradicionales, sobre todo los periódicos. La atracción del contenido gratuito también es mayor. Se da asimismo una diferencia de consumo a favor de los varones y las personas de más edad, ya que el consumo de noticias aumenta a medida que las personas jóvenes maduran (Casero-Ripollés, 2012). Sin embargo, la industria de las noticias necesita llevar a cabo una auténtica convergencia digital para proveer a las generaciones jóvenes de una experiencia de consumo multimedia que sea personalizable y relevante para ellas (Huang, 2009).

Esta breve revisión de la literatura evidencia cierto desacuerdo en cuanto a la magnitud exacta del cambio que Internet ha producido en el consumo de noticias y los factores que más capaces son de predecirlo. Esta investigación parte de unas preguntas de investigación que se explicitan a continuación:

- PI1) ¿Internet ha supuesto un cambio significativo en los niveles de consumo de noticias en los medios tradicionales? 
- PI2) ¿La composición sociodemográfica de los consumidores de noticias es muy distinta dependiendo del medio de que se trate?

- PI3) ¿Las variables sociodemográficas siguen siendo buenos predictores del consumo de noticias?

- PI4) ¿El consumo de noticias en un medio predice significativamente el consumo en los demás medios?

Las hipótesis se justifican en la literatura citada, que aunque en parte contradictoria, soporta los planteamientos mencionados. Especialmente en las contribuciones de Livingstone y Markham (2008), Ksiazek, Malthouse y Webster (2010), Mitchelstein y Boczkowski (2010), Van Cauwenberge, d'Haenens y Beentjes (2010), Waldman et al., (2011), Casero-Ripollés (2012), Abernathy (2018) y Goyanes, Artero y Zapata (2018), que están más en línea con las premisas de esta investigación.

\section{Método}

El método elegido para desarrollar este artículo es la encuesta, aunque recurriendo a la información secundaria obtenida por el Centro de Investigaciones Sociológicas (CIS) a través de los años. En concreto, algunos barómetros mensuales y otros estudios del CIS incluyen periódicamente al menos desde el año 2000 una pregunta sobre frecuencia de consumo de noticias en diferentes medios. Sobre esa base y recurriendo a ocho barómetros hasta 2009 construyó Meilán (2010) su investigación, del que este artículo es parcialmente un estudio de réplica. Siendo esto así, los resultados obtenidos en ambas publicaciones se compararán detalladamente en el epígrafe de discusión. Sin embargo hay que decir que este autor tuvo que combinar en aquella ocasión diferentes criterios de construcción de la pregunta y sus respuestas. Los dos primeros años la escala de consumo ofrecida en el cuestionario tenía seis grados, mientras que a partir de 2004 ya constó de los habituales cinco al modo clásico de Likert. A su vez, los cuatro primeros estudios entre 2000 y 2005 presentaban desagregado el consumo de radio del de televisión. Estas disfunciones en el cuestionario dificultaron sin duda la obtención de datos consistentes y fiables a lo largo de la serie temporal.

Para soslayar este problema metodológico, el artículo presente ha elegido sólo estudios del CIS que ofrecieran exactamente las mismas preguntas y opciones de respuesta en el cuestionario. Después de un somero análisis, se evidenció que el modelo A de pregunta estaba disponible para diez años entre 2006 y 2017 (todos excepto 2009 y 2010), mientras que otras dos versiones ligeramente diferentes lo estaban en cuatro años cada uno. Estos últimos estudios fueron desechados y se construyó la base de datos a partir de las matrices del CIS de los diez años mencionados, que se corresponden con los números 2632, 2700, 2749, 2914, 2960, 3001, 3041, 3114, 3156 y 3191. Las respuestas obtenidas se ciñeron a tres opciones: "lee las secciones políticas del periódico", "escucha o ve las noticias en la radio o la televisión" y "usa Internet para obtener información acerca de la política o la sociedad". Una cuarta opción de respuesta fue desechada por considerarla redundante y que no añade información relevante a la obtenida en la opción principal. Su enunciado es "aparte de las noticias, escucha o ve otros programas sobre política en la radio o la televisión".

Los estudios del CIS a los que se ha recurrido se han realizado con encuesta telefónica a una muestra representativa de la población española mayor de 18 años. El número de entrevistas realizadas en cada uno de los estudios es variable, pero van de las 2.455 de 2007 a las 3.191 de 2006, como se verá en las tablas posteriores. El software utilizado para analizar los datos de las matrices ha sido SPSS 22.0.

En el tratamiento posterior de los datos, las variables de frecuencia de consumo están recodificadas, de manera que a "todos los días" se le ha asignado cinco puntos y a "nunca", uno, como se evidencia 
en las tablas 4, 5 y 6 . Los criterios sociodemográficos con los que se han cruzado las respuestas son edad, sexo, hábitat, clase social y nivel de instrucción. A ellos se añadido la autoubicación ideológica entre 1 (izquierda) y 10 (derecha). Del mismo modo, la variable nivel de estudios de las preguntas sociodemográficas del final del cuestionario ofrecía la opción "medios universitarios" de 2006 a 2013, pero no a partir de entonces, lo que no ha supuesto una dificultad insalvable. Finalmente, para realizar las tablas 7, 8 y 9 se ha recodificado "mujer" con el valor 1 y "hombre" con el 0 , así como se ha construido la categoría de hábitat urbano con el valor 1 para municipios con 50.000 o más habitantes y de hábitat rural con el valor 0 para municipios con menos de 50.000 habitantes, lo cual constituye un estándar general en España.

La elección de la base de datos del CIS para esta investigación se justifica en su indudable profesionalidad, disponibilidad de medios técnicos y humanos y posibilidad de extraer series temporales de datos a lo largo de suficientes años, lo que aporta resultados más robustos que la aplicación de una sola encuesta en la actualidad. Asimismo interesaba contar con datos históricos que permitiesen conocer la evolución del consumo de noticias en Internet tal y como entonces fue preguntado y declarado, no como recuerdo a posteriori. El rigor en la captura y tratamiento de los datos es asimismo contrastado, lo que asegura que las matrices sean científicamente fiables.

\section{Resultados}

\subsection{Frecuencias de consumo de noticias}

Tabla 1. Frecuencia de lectura de secciones políticas en periódicos.

\begin{tabular}{|l|r|r|r|r|r|r|r|r|r|r|}
\hline & 2006 & 2007 & 2008 & 2011 & 2012 & 2013 & 2014 & 2015 & 2016 & 2017 \\
\hline Todos los dias & $16,90 \%$ & $17,00 \%$ & $16,60 \%$ & $20,60 \%$ & $22,60 \%$ & $21,20 \%$ & $20,00 \%$ & $19,20 \%$ & $22,60 \%$ & $23,70 \%$ \\
\hline 3-4 por semana & $12,50 \%$ & $13,40 \%$ & $12,00 \%$ & $12,60 \%$ & $12,60 \%$ & $10,20 \%$ & $11,00 \%$ & $10,70 \%$ & $12,20 \%$ & $10,80 \%$ \\
\hline 1-2 por semana & $15,70 \%$ & $17,00 \%$ & $16,80 \%$ & $15,30 \%$ & $15,10 \%$ & $15,30 \%$ & $13,70 \%$ & $13,30 \%$ & $12,30 \%$ & $12,80 \%$ \\
\hline Menor frecuencia & $17,90 \%$ & $18,40 \%$ & $18,60 \%$ & $17,50 \%$ & $13,20 \%$ & $14,60 \%$ & $14,50 \%$ & $16,90 \%$ & $14,70 \%$ & $14,00 \%$ \\
\hline Nunca & $36,90 \%$ & $33,90 \%$ & $35,70 \%$ & $33,70 \%$ & $36,20 \%$ & $38,60 \%$ & $40,70 \%$ & $39,60 \%$ & $38,10 \%$ & $38,50 \%$ \\
\hline NS & $0,00 \%$ & $0,10 \%$ & $0,20 \%$ & $0,00 \%$ & $0,20 \%$ & $0,10 \%$ & $0,00 \%$ & $0,20 \%$ & $0,10 \%$ & $0,20 \%$ \\
\hline NC & $0,10 \%$ & $0,20 \%$ & $0,20 \%$ & $0,20 \%$ & $0,10 \%$ & $0,00 \%$ & $0,10 \%$ & $0,10 \%$ & $0,00 \%$ & $0,00 \%$ \\
\hline N) & 3.191 & 2.455 & 2.477 & 2.472 & 2.848 & 2.485 & 2.480 & 2.493 & 2.491 & 2.487 \\
\hline
\end{tabular}

Fuente: elaboración propia a partir de los estudios del CIS números 2632, 2700, 2749, 2914, 2960, 3001, 3041, 3114, 3156 у 3191.

Los consumidores de periódicos que leen noticias diariamente han aumentado entre 2006 y 2017 desde el 16 hasta el 23 por ciento, aunque en ligero detrimento de quienes las leen con una frecuencia menor. Esto se evidencia en que el porcentaje de personas que nunca leen periódicos se ha mantenido estable entre el 36 y el 38 por ciento. Dicho de otro modo, la lectura de periódicos no ha disminuido en la década estudiada. Este dato no sería congruente con otros conocidos si se refiriese sólo a las versiones impresas. Pero resulta evidente que los encuestados han respondido haciendo referencia tanto a los diarios impresos como a otros digitales. 
RLCS, Revista Latina de Comunicación Social, 77, 55-72

[Investigación] DOI: 10.4185/RLCS-2020-1449 | ISSN 1138-5820 | Año 2020

Tabla 2. Frecuencia de escucha o visionado de noticias en radio o televisión.

\begin{tabular}{|l|r|r|r|r|r|r|r|r|r|r|}
\hline & 2006 & 2007 & 2008 & 2011 & 2012 & 2013 & 2014 & 2015 & 2016 & 2017 \\
\hline Todos los dias & $67,00 \%$ & $65,00 \%$ & $71,90 \%$ & $68,80 \%$ & $69,10 \%$ & $64,60 \%$ & $68,70 \%$ & $64,40 \%$ & $65,20 \%$ & $67,70 \%$ \\
\hline 3-4 por semana & $18,40 \%$ & $17,50 \%$ & $14,80 \%$ & $15,60 \%$ & $16,20 \%$ & $15,90 \%$ & $13,50 \%$ & $16,70 \%$ & $15,50 \%$ & $14,10 \%$ \\
\hline $1-2$ por semana & $6,30 \%$ & $8,40 \%$ & $5,90 \%$ & $7,50 \%$ & $6,10 \%$ & $8,90 \%$ & $8,00 \%$ & $7,80 \%$ & $8,30 \%$ & $7,20 \%$ \\
\hline Menor frecuencia & $4,70 \%$ & $5,10 \%$ & $3,10 \%$ & $3,50 \%$ & $4,10 \%$ & $4,10 \%$ & $4,50 \%$ & $6,10 \%$ & $5,60 \%$ & $4,50 \%$ \\
\hline Nunca & $3,60 \%$ & $4,00 \%$ & $4,00 \%$ & $4,50 \%$ & $4,40 \%$ & $6,50 \%$ & $5,20 \%$ & $5,00 \%$ & $5,30 \%$ & $6,50 \%$ \\
\hline NS & $0,00 \%$ & $0,00 \%$ & $0,10 \%$ & $0,00 \%$ & $0,00 \%$ & & $0,00 \%$ & & $0,00 \%$ & \\
\hline NC & $0,00 \%$ & $0,10 \%$ & $0,10 \%$ & $0,10 \%$ & $0,00 \%$ & & $0,00 \%$ & $0,00 \%$ & $0,10 \%$ & $0,00 \%$ \\
\hline N) & 3.191 & 2.455 & 2.477 & 2.472 & 2.848 & 2.485 & 2.480 & 2.493 & 2.491 & 2.487 \\
\hline
\end{tabular}

Fuente: elaboración propia a partir de los estudios del CIS números 2632, 2700, 2749, 2914, 2960, $3001,3041,3114,3156$ y 3191.

Sin embargo, el porcentaje de españoles que consumen noticias en radio o televisión a diario es mucho más alto (dos tercios) y se ha mantenido estable entre 2006 y 2017. Las frecuencias intermedias son similares en la serie 2006-2017 y aumentan ligeramente aquellos que nunca consultan las noticias audiovisuales: del 3 al 6 por ciento.

Tabla 3. Frecuencia de búsqueda de información política o social en Internet.

\begin{tabular}{|l|r|r|r|r|r|r|r|r|r|r|}
\hline & 2006 & 2007 & 2008 & 2011 & 2012 & 2013 & 2014 & 2015 & 2016 & 2017 \\
\hline Todos los dias & $4,20 \%$ & $5,70 \%$ & $6,40 \%$ & $10,60 \%$ & $15,30 \%$ & $15,30 \%$ & $17,10 \%$ & $15,80 \%$ & $18,90 \%$ & $25,90 \%$ \\
\hline 3-4 por semana & $3,80 \%$ & $4,60 \%$ & $4,80 \%$ & $6,50 \%$ & $8,10 \%$ & $7,90 \%$ & $7,80 \%$ & $7,20 \%$ & $8,50 \%$ & $8,80 \%$ \\
\hline 1-2 por semana & $3,50 \%$ & $5,10 \%$ & $4,80 \%$ & $7,10 \%$ & $6,80 \%$ & $7,10 \%$ & $6,80 \%$ & $8,00 \%$ & $9,20 \%$ & $8,50 \%$ \\
\hline Menor frecuencia & $9,80 \%$ & $11,00 \%$ & $9,50 \%$ & $9,30 \%$ & $8,20 \%$ & $8,70 \%$ & $9,70 \%$ & $12,20 \%$ & $11,10 \%$ & $9,90 \%$ \\
\hline Nunca & $78,00 \%$ & $72,80 \%$ & $73,60 \%$ & $65,70 \%$ & $60,70 \%$ & $60,40 \%$ & $57,70 \%$ & $56,10 \%$ & $51,50 \%$ & $46,40 \%$ \\
\hline NS & $0,40 \%$ & $0,30 \%$ & $0,50 \%$ & $0,40 \%$ & $0,50 \%$ & $0,40 \%$ & $0,60 \%$ & $0,60 \%$ & $0,40 \%$ & $0,40 \%$ \\
\hline NC & $0,40 \%$ & $0,50 \%$ & $0,30 \%$ & $0,40 \%$ & $0,40 \%$ & $0,10 \%$ & $0,30 \%$ & $0,10 \%$ & $0,40 \%$ & $0,10 \%$ \\
\hline N) & 3.191 & 2.455 & 2.477 & 2.472 & 2.848 & 2.485 & 2.480 & 2.493 & 2.491 & 2.487 \\
\hline
\end{tabular}

Fuente: elaboración propia a partir de los estudios del CIS números 2632, 2700, 2749, 2914, 2960, $3001,3041,3114,3156$ y 3191.

Sin embargo, la frecuencia de búsqueda de información política o social en Internet ha aumentado significativamente entre 2006 y 2017. Aquellos que lo hacen todos los días se han multiplicado por cinco: del 4 al 25 por ciento. Asimismo, los que lo hacen con una frecuencia de entre uno y cuatro días por semana suben del 3 al 8 por ciento. Y finalmente, los no consumidores de noticias en Internet se han reducido desde el 78 al 46 por ciento, casi la mitad. 
RLCS, Revista Latina de Comunicación Social, 77, 55-72

[Investigación] DOI: 10.4185/RLCS-2020-1449 | ISSN 1138-5820 | Año 2020

\subsection{Perfil sociodemográfico de los consumidores de noticias}

Tabla 4. Perfil sociodemográfico de los lectores de secciones políticas en periódicos.

\begin{tabular}{|c|c|c|c|c|c|c|c|c|c|c|c|c|c|c|c|c|c|c|c|c|}
\hline & \multicolumn{2}{|c|}{2006} & \multicolumn{2}{|c|}{2007} & \multicolumn{2}{|c|}{2008} & \multicolumn{2}{|c|}{2011} & \multicolumn{2}{|c|}{2012} & \multicolumn{2}{|c|}{2013} & \multicolumn{2}{|c|}{2014} & \multicolumn{2}{|c|}{2015} & \multicolumn{2}{|c|}{2016} & \multicolumn{2}{|c|}{2017} \\
\hline Sexo & Media & $\mathrm{N}$ & Media & $\mathrm{N}$ & \begin{tabular}{|l|} 
Media \\
\end{tabular} & $\mathrm{N}$ & Media & $\mathrm{N}$ & Media & $\mathrm{N}$ & Media & $\mathrm{N}$ & Media & $\mathrm{N}$ & Media & $\mathrm{N}$ & Media & $\mathrm{N}$ & Media & $\mathrm{N}$ \\
\hline Hombre & 2,68 & $49,8 \%$ & 2,96 & $48,8 \%$ & 2,84 & $48,9 \%$ & 3,03 & $49.2 \%$ & 3,00 & $49,0 \%$ & 2.96 & $49,0 \%$ & 2,85 & $48,8 \%$ & 2.78 & $48,3 \%$ & 2,94 & $48,4 \%$ & 2,97 & $48,4 \%$ \\
\hline Mujer & 2,12 & $30.2 \%$ & 2,3 & $51,2 \%$ & 2,31 & $51,1 \%$ & 2,39 & $50,8 \%$ & 2,49 & $51,0 \%$ & 2,28 & $51,0 \%$ & 2,27 & $51,2 \%$ & 2,32 & $51,7 \%$ & 2,41 & $51,6 \%$ & 2,42 & $51,6 \%$ \\
\hline Total & 2,4 & 3.191 & 2.63 & \begin{tabular}{|l|l|}
2.455 \\
\end{tabular} & 2,57 & 2.477 & 2.70 & 2.472 & 2,74 & 2.484 & 2.61 & \begin{tabular}{|l|l|}
2.485 \\
\end{tabular} & 2.56 & 2,480 & 2.55 & \begin{tabular}{|l|}
2.493 \\
\end{tabular} & 2.67 & 2.491 & 2,68 & \begin{tabular}{|l|l|}
2.487 \\
\end{tabular} \\
\hline Hábitat & Media & $\mathrm{N}$ & Media & $\mathrm{N}$ & \begin{tabular}{|l|} 
Media \\
\end{tabular} & $\mathrm{N}$ & Media & $\mathrm{N}$ & Media & $\mathrm{N}$ & Media & $\mathrm{N}$ & Media & $\mathrm{N}$ & Media & $\mathrm{N}$ & Media & $\mathrm{N}$ & Media & $\mathrm{N}$ \\
\hline Rural & 2.22 & $53.8 \%$ & 2,4 & $48,6 \%$ & \begin{tabular}{|l|}
2,40 \\
\end{tabular} & $47,5 \%$ & 2,43 & $47,3 \%$ & 2.54 & $47,6 \%$ & 2,37 & $47,3 \%$ & 2,35 & $47.1 \%$ & 2,38 & $48,6 \%$ & 2,40 & $48.2 \%$ & 2,42 & $48,9 \%$ \\
\hline Urbano & 2,61 & $46.2 \%$ & 2.84 & $51,4 \%$ & 2,73 & $52.5 \%$ & 2,95 & $52,7 \%$ & 2.91 & $52,4 \%$ & 2,84 & $52,7 \%$ & 2,74 & $52.9 \%$ & 2.70 & $51,4 \%$ & 2.92 & $51.8 \%$ & 2,94 & $51,1 \%$ \\
\hline Total & 2,4 & 3.191 & 2,63 & 2.455 & 2,57 & 2.477 & 2,70 & 2.472 & 2,74 & 2.484 & 2,61 & 2.485 & 2,56 & 2.480 & 2,55 & 2.493 & 2,67 & 2.491 & 2,68 & 2.487 \\
\hline Edad & Media & $\mathrm{N}$ & Media & $\mathrm{N}$ & \begin{tabular}{|l|} 
Media \\
\end{tabular} & $\mathrm{N}$ & Media & $\mathrm{N}$ & Media & $\mathrm{N}$ & Media & $\mathrm{N}$ & Media & $\mathrm{N}$ & Media & $\mathrm{N}$ & Media & $\mathrm{N}$ & Media & $\mathrm{N}$ \\
\hline Menos de 34 & 2,37 & $53,5 \%$ & 2.55 & $31,4 \%$ & 2.54 & $30,9 \%$ & 2,60 & $29,7 \%$ & 2,61 & $28,2 \%$ & 2,46 & $28,0 \%$ & 2,48 & $25,4 \%$ & 2,35 & $22,7 \%$ & 2,47 & $22,4 \%$ & 2,51 & $21,9 \%$ \\
\hline De 35 a 49 & 2,66 & $18,5 \%$ & 2,85 & $27,7 \%$ & 2,66 & $27,9 \%$ & 2,92 & $28,0 \%$ & 2.98 & $29,3 \%$ & 2,79 & $29,1 \%$ & 2,70 & $30.0 \%$ & 2,75 & $29,0 \%$ & 2,83 & $29,3 \%$ & 2,83 & $28,9 \%$ \\
\hline De 50 a 64 & 2,49 & $14,0 \%$ & 2.74 & $20,6 \%$ & 2,77 & $21,0 \%$ & 2,89 & $22,3 \%$ & 2,88 & $22.3 \%$ & 2.84 & $22,3 \%$ & 2.74 & $23,5 \%$ & 2.75 & $24,7 \%$ & 2.94 & $24.1 \%$ & 2,93 & $24,9 \%$ \\
\hline 65 y mís & 2,07 & $14,0 \%$ & 2,33 & $20,3 \%$ & 2,29 & $20.2 \%$ & 2,33 & $19,9 \%$ & 2,40 & $20.2 \%$ & 2,34 & $20,6 \%$ & 2.23 & $21,1 \%$ & 2,28 & $23,5 \%$ & 2.39 & $24,2 \%$ & 2,41 & $24,4 \%$ \\
\hline Total & 2,4 & 3.191 & 2,63 & 2.455 & 2,57 & 2.477 & 2,70 & 2.472 & 2,74 & 2.484 & 2,61 & 2.485 & 2,56 & 2.480 & 2,55 & 2.493 & 2.67 & 2.491 & 2,68 & 2.487 \\
\hline Estatus sociocconómico & Media & $\mathrm{N}$ & Media & $\mathrm{N}$ & Media & $\mathrm{N}$ & Media & $\mathrm{N}$ & Media & $\mathrm{N}$ & Media & $\mathrm{N}$ & Media & $\mathrm{N}$ & Media & $\mathrm{N}$ & Media & $\mathrm{N}$ & Media & $\mathrm{N}$ \\
\hline Clase alta'media alta & 3,14 & $15.9 \%$ & 3,39 & $17,0 \%$ & 3,32 & $16,8 \%$ & 3,44 & $16,0 \%$ & 3,48 & $18,4 \%$ & 3,46 & $17,4 \%$ & 3,46 & $17,2 \%$ & 3,35 & $18,8 \%$ & 3,52 & $19,0 \%$ & 3,46 & $20,2 \%$ \\
\hline Nuevas clases medias & 2.74 & $19.0 \%$ & 2,81 & $21,1 \%$ & 2,84 & $19.9 \%$ & 2.97 & $21,5 \%$ & 3.01 & $21.8 \%$ & 2.78 & $23,5 \%$ & 2,67 & $24,8 \%$ & 2,74 & $25,0 \%$ & 2,86 & $23,0 \%$ & 2,96 & $23,5 \%$ \\
\hline Viejas clases medias & 2,26 & $12,6 \%$ & 2,34 & $17,7 \%$ & 2,28 & $18,4 \%$ & 2,49 & $16,1 \%$ & 2,40 & $15,1 \%$ & 2,53 & $12,8 \%$ & 2,50 & $11,7 \%$ & 2,41 & $13,6 \%$ & 2,43 & $14.2 \%$ & 2,49 & $14,5 \%$ \\
\hline Obreros cualificados & 2,19 & $34,4 \%$ & 2,41 & $31,4 \%$ & 2,38 & $33,1 \%$ & 2,49 & $33,1 \%$ & 2.51 & $31,3 \%$ & 2,28 & $33,1 \%$ & 2,23 & $32,1 \%$ & 2,21 & $28,9 \%$ & 2,40 & $29,3 \%$ & 2,32 & $27,3 \%$ \\
\hline Obrero & 1,88 & $18.1 \%$ & 2,17 & $12,8 \%$ & 2,05 & $11,8 \%$ & 2.15 & $13,3 \%$ & 2,17 & $13,5 \%$ & 2,12 & $13,2 \%$ & 2,00 & $14.2 \%$ & 1.91 & $13,8 \%$ & 2.04 & $14,5 \%$ & 1,99 & $14,5 \%$ \\
\hline Total & 2,4 & 3.092 & 2,63 & 2.364 & 2,57 & 2.434 & 2,70 & 2.430 & 2,74 & 2.445 & 2,61 & 2.447 & 2,56 & 2.427 & 2.55 & 2.428 & 2,67 & 2.442 & 2,68 & 2.438 \\
\hline Nivel de estudios & Media & $\mathrm{N}$ & Media & $\mathrm{N}$ & \begin{tabular}{|l|} 
Media \\
\end{tabular} & $\mathrm{N}$ & Media & $\mathrm{N}$ & Media & $N$ & Media & $\mathrm{N}$ & Media & $\mathrm{N}$ & Media & $\mathrm{N}$ & Media & $\mathrm{N}$ & Media & $\mathrm{N}$ \\
\hline Sin estudios & 1,41 & $8,1 \%$ & 1,74 & $9,2 \%$ & 1,69 & $8,0 \%$ & 1,37 & $7,0 \%$ & 1.53 & $6.5 \%$ & 1.53 & $6,0 \%$ & 1.25 & $5,6 \%$ & 1,44 & $5,5 \%$ & 1.41 & $4,7 \%$ & 1,42 & $5,2 \%$ \\
\hline Primaria & 2,05 & $43.1 \%$ & 2,27 & $45,2 \%$ & 2,22 & $44,1 \%$ & 2,36 & $44,4 \%$ & 2,39 & $45,3 \%$ & 2,16 & $19,6 \%$ & 1.96 & $20,3 \%$ & 2,02 & $18,0 \%$ & 2,04 & $18,1 \%$ & 2,08 & $18,5 \%$ \\
\hline Secur & 2.67 & $14,9 \%$ & 3,15 & $11.8 \%$ & 3,00 & $13,1 \%$ & 3,07 & $13,9 \%$ & 3,08 & $11,8 \%$ & 2.49 & $38,6 \%$ & 2,54 & $38,5 \%$ & 2,42 & $36,6 \%$ & 2,52 & $37.1 \%$ & 2,59 & $35,7 \%$ \\
\hline F.P & 2,65 & $17,0 \%$ & 2,79 & $15,8 \%$ & 2,60 & $16,8 \%$ & 2,86 & $17,5 \%$ & 2.90 & $16,8 \%$ & 2.68 & $16,9 \%$ & 2.68 & $17,0 \%$ & 2.55 & $19.2 \%$ & 2,79 & $19.1 \%$ & 2,8 & $18,8 \%$ \\
\hline Medios universitarios & 3,16 & $8.2 \%$ & 3,06 & $7,8 \%$ & 3,31 & $8,4 \%$ & 3,54 & $6.9 \%$ & 3,47 & $8,0 \%$ & & & & & & & & & & \\
\hline Superiores & 3,43 & $8,4 \%$ & 3,76 & $10,2 \%$ & 3,63 & $9.6 \%$ & 3,74 & $10,3 \%$ & 3,71 & $11,6 \%$ & 3,64 & $18,8 \%$ & 3,52 & $18,6 \%$ & 3,51 & $20,6 \%$ & 3,65 & $21.1 \%$ & 3,55 & $21,9 \%$ \\
\hline Total & 2,4 & 3.191 & 2,63 & 2.455 & 2,57 & 2.474 & 2,70 & 2.461 & 2,74 & 2.477 & 2,61 & 2.479 & 2,56 & 2.478 & 2,55 & 2.491 & 2.67 & 2.485 & 2,68 & 2.485 \\
\hline Ideolo & Media & $\mathrm{N}$ & Media & $\mathrm{N}$ & \begin{tabular}{|l|} 
Media \\
\end{tabular} & $\mathrm{N}$ & Media & $\mathrm{N}$ & Media & $\mathrm{N}$ & Media & $\mathrm{N}$ & Media & $\mathrm{N}$ & Media & $\mathrm{N}$ & Media & $\mathrm{N}$ & Media & \\
\hline 1 (lzquierda) & 3,05 & $7,3 \%$ & 2,92 & $4,3 \%$ & 2.87 & $4,4 \%$ & 2,84 & $4,4 \%$ & 3,13 & $4,9 \%$ & 2,97 & $4,8 \%$ & 2.90 & $6,6 \%$ & 3,29 & $5,3 \%$ & 2,93 & $6,6 \%$ & 3,36 & $4,7 \%$ \\
\hline 2 & 2,76 & $10,7 \%$ & 3,18 & $5,4 \%$ & 3,13 & $5,2 \%$ & 3,09 & $6,1 \%$ & 3,18 & $4,9 \%$ & 3,16 & $6,8 \%$ & 3,15 & $8.0 \%$ & 3,13 & $5,1 \%$ & 3,12 & $6,7 \%$ & 3,04 & $5,7 \%$ \\
\hline 3 & 2,52 & $16.9 \%$ & 2.79 & $17,5 \%$ & 2,87 & $16,0 \%$ & 2,92 & $15,9 \%$ & 2,94 & $19.9 \%$ & 2,83 & $19.7 \%$ & 2.84 & $20,3 \%$ & 2.76 & $17.8 \%$ & 2.95 & $18.9 \%$ & 2.97 & $17,0 \%$ \\
\hline 4 & 2,28 & $15,5 \%$ & 2,67 & $19,9 \%$ & 2,59 & $18,6 \%$ & 2,74 & $15,6 \%$ & 2,78 & $18,1 \%$ & 2,86 & $17,2 \%$ & 2,65 & $18,6 \%$ & 2,64 & $15,7 \%$ & 2.75 & $15,6 \%$ & 2,76 & $16,1 \%$ \\
\hline 5 & 2,41 & $28,8 \%$ & 2,65 & $28,7 \%$ & 2,65 & $27,7 \%$ & 2,73 & $28,2 \%$ & 2,78 & $25.8 \%$ & 2,50 & $29.8 \%$ & 2,58 & $22,6 \%$ & 2,44 & $26,5 \%$ & 2,65 & $22,8 \%$ & 2,76 & $27,0 \%$ \\
\hline 6 & 2,81 & $7,5 \%$ & 2,83 & $10,4 \%$ & 2,69 & $12,4 \%$ & 3,02 & $10,4 \%$ & 2.89 & $10.5 \%$ & 2.79 & $8,7 \%$ & 2,70 & $9,7 \%$ & 2.61 & $12,3 \%$ & 2,76 & $11.5 \%$ & 2.99 & $11.9 \%$ \\
\hline 7 & 2,58 & $6.8 \%$ & 2,84 & $6,9 \%$ & 2,62 & $7,7 \%$ & 2,99 & $9,7 \%$ & 2.85 & $8,4 \%$ & 3,02 & $6,6 \%$ & 2.90 & $6.8 \%$ & 2,72 & $7,9 \%$ & 2.84 & $7,9 \%$ & 2,67 & $8,0 \%$ \\
\hline 8 & 2,63 & $4,5 \%$ & 2,5 & $4,3 \%$ & 3,08 & $4.9 \%$ & 2.77 & $5,6 \%$ & 2,97 & $5,1 \%$ & 2,39 & $4,3 \%$ & 2,67 & $4.9 \%$ & 2,57 & $5.4 \%$ & 2.67 & $6.4 \%$ & 2,68 & $5,9 \%$ \\
\hline 9 & 2,94 & $0,7 \%$ & 3.11 & $0,9 \%$ & 2,42 & $1.2 \%$ & 2.69 & $2.1 \%$ & 2,90 & $1,6 \%$ & 2,81 & $1.1 \%$ & 2,47 & $1,0 \%$ & 2,36 & $2,4 \%$ & 2.50 & $1.8 \%$ & 2.49 & $1,9 \%$ \\
\hline 10 (Derecha) & 2,69 & $1,2 \%$ & 2,36 & $1,6 \%$ & 2,86 & $1.8 \%$ & 2,68 & $1,9 \%$ & 2,84 & $1,0 \%$ & 2,70 & $1,0 \%$ & 2,74 & $1,6 \%$ & 2,27 & $1,6 \%$ & 2.95 & $1,8 \%$ & 2,43 & $1,7 \%$ \\
\hline Total & 2.4 & 2.574 & 2,63 & 2.040 & 2,57 & 1.965 & 2.70 & 2.005 & 2.74 & 1.971 & 2,61 & 1.981 & 2,56 & 1.961 & 2.55 & 2.101 & 2.67 & 2.068 & 2,68 & 2.077 \\
\hline
\end{tabular}

Fuente: elaboración propia a partir de los estudios del CIS números 2632, 2700, 2749, 2914, 2960, $3001,3041,3114,3156$ y 3191.

Los lectores de periódicos son más frecuentemente masculinos y urbanos que femeninos y rurales de manera consistente a lo largo de la serie. En cuanto a la edad, los lectores de edades intermedias mayores de 34 años y menores de 65 leen más frecuentemente que los de edades más jóvenes o mayores. Con respecto a las clases sociales, cuanto más altas son, más frecuentemente consumen prensa. Lo mismo ocurre con el nivel de estudios: a mayor formación, mayor frecuencia en el consumo de diarios. Finalmente, cuanto más de izquierdas se declara el encuestado, más frecuentemente lee la prensa, aunque las diferencias son poco importantes. Del mismo modo, en la serie observada los cambios a lo largo de la década son menores. 
RLCS, Revista Latina de Comunicación Social, 77, 55-72

[Investigación] DOI: 10.4185/RLCS-2020-1449 | ISSN 1138-5820 | Año 2020

Tabla 5. Perfil sociodemográfico de la audiencia de noticias en radio o televisión.

\begin{tabular}{|c|c|c|c|c|c|c|c|c|c|c|c|c|c|c|c|c|c|c|c|c|}
\hline & \multicolumn{2}{|c|}{2006} & \multicolumn{2}{|c|}{2007} & \multicolumn{2}{|c|}{2008} & \multicolumn{2}{|c|}{2011} & \multicolumn{2}{|c|}{2012} & \multicolumn{2}{|c|}{2013} & \multicolumn{2}{|c|}{2014} & \multicolumn{2}{|c|}{2015} & \multicolumn{2}{|c|}{2016} & \multicolumn{2}{|c|}{2017} \\
\hline Sexo & Media & $\mathrm{N}$ & Media & $\mathrm{N}$ & Media & $\mathrm{N}$ & Media & $\mathrm{N}$ & Media & $\mathrm{N}$ & Media & $\mathrm{N}$ & Media & $\mathrm{N}$ & Media & $\mathrm{N}$ & Media & $\mathrm{N}$ & Media & $\mathrm{N}$ \\
\hline Hombre & 4,32 & $49,8 \%$ & 4,42 & $48,8 \%$ & 4,51 & $48,9 \%$ & 4,45 & $49,2 \%$ & 4,48 & \begin{tabular}{|l|}
$49,0 \%$ \\
\end{tabular} & 4,30 & $49,0 \%$ & 4,41 & $48.8 \%$ & 4,34 & $48,3 \%$ & 4,38 & $48,4 \%$ & 4,32 & $48,4 \%$ \\
\hline \begin{tabular}{|l|} 
Mujer \\
\end{tabular} & 4,25 & $50.2 \%$ & 4,29 & $51,2 \%$ & 4,45 & $51,1 \%$ & 4,38 & $50,8 \%$ & 4,36 & $51,0 \%$ & 4,26 & $51,0 \%$ & 4,32 & $51,2 \%$ & 4,26 & $51,7 \%$ & 4,23 & $51,6 \%$ & 4,32 & $51,6 \%$ \\
\hline Total & 4,31 & 3.191 & 4,35 & 2.455 & 4,48 & 477 & 4,41 & 2.472 & 4,42 & 2.484 & 4.28 & 2.485 & 4,33 & 2.480 & 4,30 & 2.493 & 4,30 & 2.491 & 4,32 & 2.487 \\
\hline Habitat & ledia & $\mathrm{N}$ & Media & $\mathrm{N}$ & Media & $\mathrm{N}$ & Media & $\mathrm{N}$ & Media & $\mathrm{N}$ & Media & $\mathrm{N}$ & Media & $\mathrm{N}$ & Media & $\mathrm{N}$ & Media & $\mathrm{N}$ & Media & \\
\hline Rural & 1717 & $53.8 \%$ & 4,3 & $6 \%$ & 4.45 & $47,5 \%$ & 4,36 & $47,3 \%$ & 4,37 & \begin{tabular}{|l|}
$47,6 \%$ \\
\end{tabular} & 4,27 & $47,3 \%$ & 4,38 & $47,1 \%$ & 4,28 & $8.6 \%$ & 4,23 & $48.2 \%$ & 4,27 & $48,9 \%$ \\
\hline Urbano & 1475 & $46.2 \%$ & 4,4 & $1.4 \%$ & 4,51 & $52.5 \%$ & 4,46 & $52.7 \%$ & 4,46 & $52.4 \%$ & 4.29 & $52,7 \%$ & 4,35 & $52.9 \%$ & 4,31 & $51,4 \%$ & 4,37 & $51.8 \%$ & 4,38 & $51,1 \%$ \\
\hline Total & 3192 & 3.191 & 4,35 & 2.455 & 4,48 & 2.477 & 4,41 & 2.472 & 4,42 & 2.484 & 4,28 & 2.485 & 4,33 & 2.480 & 4,30 & 2.493 & 4,30 & 2.491 & 4,32 & 2.487 \\
\hline Edad & Iedia & $\mathrm{N}$ & Media & $\mathrm{N}$ & Media & $\mathrm{N}$ & Media & $\mathrm{N}$ & Media & $\mathrm{N}$ & Media & $\mathrm{N}$ & Media & $\mathrm{N}$ & Media & $\mathrm{N}$ & Media & $\mathrm{N}$ & Media & $\mathrm{N}$ \\
\hline Menos de 34 & 4,21 & $53,5 \%$ & 4,17 & $.4 \%$ & 4,35 & $0,9 \%$ & 4,22 & $29,7 \%$ & 4,26 & $28.2 \%$ & 4,00 & $28,0 \%$ & 4,09 & $5,4 \%$ & 3,92 & $2,7 \%$ & 3,97 & $22,4 \%$ & 4,03 & $21,9 \%$ \\
\hline$D e 35$ a 49 & 4,5 & $18,5 \%$ & 4,43 & $7.7 \%$ & 4,58 & $27,9 \%$ & 4,46 & $28,0 \%$ & 4,47 & $29,3 \%$ & 4,31 & $29,1 \%$ & 4,38 & $30,0 \%$ & 4,30 & $9,0 \%$ & 4,31 & $29,3 \%$ & 4,21 & $28,9 \%$ \\
\hline De 50a64 & 4,48 & $14,0 \%$ & 4,49 & $20,6 \%$ & 4,55 & $21,0 \%$ & 4.55 & $22,3 \%$ & 4,54 & $22.3 \%$ & 4,45 & $22,3 \%$ & 4,52 & $23.5 \%$ & 4.51 & $24,7 \%$ & 4,45 & $24,1 \%$ & 4.51 & $24,9 \%$ \\
\hline 65 y más & 4.25 & $14,0 \%$ & 4,4 & $20,3 \%$ & 4,49 & $20.2 \%$ & 4,48 & $19,9 \%$ & 4,44 & $20,2 \%$ & 4,43 & $20,6 \%$ & 4,51 & $21,1 \%$ & 4,44 & $23,5 \%$ & 4,47 & $24,2 \%$ & 4,53 & $24,4 \%$ \\
\hline Total & 4,31 & 3.191 & 4,35 & 2.455 & 4,48 & 2.477 & 4,41 & 2.472 & 4,42 & 2.484 & 4,28 & 2.485 & 4,36 & 2.480 & 4,30 & 2.493 & 4,30 & 2.491 & 4,32 & 2.487 \\
\hline Estatu & Iedia & $\mathrm{N}$ & Media & $\mathrm{N}$ & Media & $N$ & \begin{tabular}{|l|} 
Media \\
\end{tabular} & $\mathrm{N}$ & Media & $\mathrm{N}$ & Media & $\mathrm{N}$ & Media & $\mathrm{N}$ & Media & $\mathrm{N}$ & Media & $\mathrm{N}$ & Media & \\
\hline Clase al & 4,56 & $15,9 \%$ & 4,54 &, $0 \%$ & 4,65 & $16,8 \%$ & 4,54 & $16,0 \%$ & 4,54 & \begin{tabular}{|l|}
$18,4 \%$ \\
\end{tabular} & 4,42 & $17,4 \%$ & 4,48 & $17,2 \%$ & 4,46 & $8,8 \%$ & 4,46 & $19.0 \%$ & 4,39 & $20,2 \%$ \\
\hline Nuevas & 4,43 & $19.0 \%$ & 4,38 & $.1 \%$ & 4,53 & $19,9 \%$ & 4,45 & $21,5 \%$ & 4,50 & $21.8 \%$ & 4.31 & $23,5 \%$ & 4,39 & $24,8 \%$ & 4,30 & $5,0 \%$ & 4,32 & $23,0 \%$ & 4,35 & $23,5 \%$ \\
\hline Vieja & 4,3 & $12.6 \%$ & 4,3 & $17,7 \%$ & 4,40 & $18,4 \%$ & 4,38 & $16,1 \%$ & 4,33 & $15.1 \%$ & 4,29 & $12,8 \%$ & 4,45 & $11,7 \%$ & 4,39 & $13,6 \%$ & 4,45 & $14.2 \%$ & 4,42 & $14,5 \%$ \\
\hline $06 \mathrm{r}$ & 4.23 & $34,4 \%$ & 4,3 & $.4 \%$ & 4,46 & $33.1 \%$ & 4,38 & $33,1 \%$ & 4,39 & $31,3 \%$ & 4,23 & $33,1 \%$ & 4,35 & $32,1 \%$ & 4,19 & $28,9 \%$ & 4,22 & $29,3 \%$ & 4,25 & $27,3 \%$ \\
\hline Obreno & 4,15 & $18,1 \%$ & 4,27 & $12,8 \%$ & 4,39 & $11.8 \%$ & 4,30 & $13,3 \%$ & 4.29 & $13,5 \%$ & 4,19 & $13,2 \%$ & 4,17 & $14.2 \%$ & 4,21 & $13,8 \%$ & 4,11 & $14,5 \%$ & 4,19 & $14,5 \%$ \\
\hline Total & 4,31 & 3.092 & 4,35 & 2.364 & 4,48 & 2.434 & 4,41 & 2.430 & 4,42 & 2.445 & 4,28 & 2.447 & 4,36 & 2.427 & 4,30 & 2.428 & 4,30 & 2.442 & 4,32 & 2.438 \\
\hline Nivel de estudios & Media & $\mathrm{N}$ & Media & $\mathrm{N}$ & Media & $\mathrm{N}$ & Media & $\mathrm{N}$ & Media & $\mathrm{N}$ & Media & $\mathrm{N}$ & Media & $\mathrm{N}$ & Media & $\mathrm{N}$ & Media & $\mathrm{N}$ & Media & $\mathrm{N}$ \\
\hline Sin es & 3,99 & $8,1 \%$ & 4,19 & $9.2 \%$ & 4,20 & $8,0 \%$ & 4.25 & $7,0 \%$ & 4,07 & $6.5 \%$ & 4,09 & $6,0 \%$ & 4,18 & $5,6 \%$ & 3,99 & $5,5 \%$ & 4,19 & $4,7 \%$ & 4,09 & $5,2 \%$ \\
\hline Prin & 4,23 & $43,1 \%$ & 4,31 & $5.2 \%$ & 4,46 & $44,1 \%$ & 4,39 & $44,4 \%$ & 4,38 & $45,3 \%$ & 4,29 & $19,6 \%$ & 4,36 & $20,3 \%$ & 4,31 & $18,0 \%$ & 4,29 & $18,1 \%$ & 4,33 & $18,5 \%$ \\
\hline Secur & 4,33 & $14,9 \%$ & 4,41 & $11.8 \%$ & 4,47 & $13.1 \%$ & 4,46 & $13,9 \%$ & 4,47 & $11,8 \%$ & 4,25 & $38,6 \%$ & 4,37 & $38,5 \%$ & 4,25 & $36,6 \%$ & 4,21 & $37.1 \%$ & 4,31 & $35,7 \%$ \\
\hline F.P & 4,38 & $17,0 \%$ & 4,35 & $15,8 \%$ & 50 & $16.8 \%$ & 4,38 & $17,5 \%$ & 4,48 & $16,8 \%$ & 4.28 & $6,9 \%$ & 4,35 & $17,0 \%$ & 4,23 & $19,2 \%$ & 4,33 & $19.1 \%$ & 4,27 & $18,8 \%$ \\
\hline Medic & 4,56 & $8,2 \%$ & 4,46 & $7,8 \%$ & 4,64 & $8,4 \%$ & 4,57 & $6,9 \%$ & 4,62 & $8,0 \%$ & & & & & & & & & & \\
\hline Superic & 57 & $4 \%$ & 4,5 & $10,2 \%$ & & & 4,52 & $10,3 \%$ & 4,14 & $11,6 \%$ & 4.39 & $18,8 \%$ & 4,44 & $18,6 \%$ & 4.50 & $20,6 \%$ & 4,47 & $21.1 \%$ & 4,44 & $21,9 \%$ \\
\hline Total & 31 & 3.191 & 4,35 & 2.455 & 48 & 2.474 & 4,41 & 2.461 & 4,42 & \begin{tabular}{|l|}
2.477 \\
\end{tabular} & 4,28 & 2.479 & 36 & 2.478 & 4,30 & 2.491 & 4,30 & 2.485 & 4,32 & 2.485 \\
\hline & Iedia & $\mathrm{N}$ & Media & $\mathrm{N}$ & ledia & $\mathrm{N}$ & Iedia & $\mathrm{N}$ & Media & $\mathrm{N}$ & Iedia & $\mathrm{N}$ & Media & $\mathrm{N}$ & Media & $\mathrm{N}$ & Media & $\mathrm{N}$ & Iedia & $\mathrm{N}$ \\
\hline 1 (lzquierda) & 4,61 & $3 \%$ & 4,57 & $4,3 \%$ & 4,52 & $4 \%$ & 4,20 & $4,4 \%$ & 4,48 & $4,9 \%$ & 4,38 & $4,8 \%$ & 4,74 & $6.6 \%$ & 4,59 & $5,3 \%$ & 4,39 & $6,6 \%$ & 4,4 & $4,7 \%$ \\
\hline 2 & 4,38 & $10,7 \%$ & 4,36 & $5,4 \%$ & 4,59 & $5.2 \%$ & 4,56 & $6,1 \%$ & 4,54 & $4,9 \%$ & 4,47 & $6,8 \%$ & 4,46 & $8,0 \%$ & 4,50 & $5,1 \%$ & 4,53 & $6,7 \%$ & 4,39 & $5.7 \%$ \\
\hline 3 & & $16.9 \%$ & 4.54 & $17,5 \%$ & 56 & $16,0 \%$ & 4.50 & $15,9 \%$ & 4,51 & $19.9 \%$ & 4,37 & $19,7 \%$ & 4,43 & $20,3 \%$ & 4,35 & $17.8 \%$ & 37 & $18.9 \%$ & 4,36 & $17,0 \%$ \\
\hline 4 & & $15,5 \%$ & & & & & 4,39 & $15,6 \%$ & 4,52 & $18,1 \%$ & 45 & $17,2 \%$ & 4,51 & & 4,38 & & 33 & $15,6 \%$ & 4.35 & $16,1 \%$ \\
\hline 5 & 35 & $28,8 \%$ & 37 & $.7 \%$ & 4.51 & $27,7 \%$ & 4,47 & $28,2 \%$ & 4,48 & $25.8 \%$ & 4,27 & $29,8 \%$ & 4,37 & $22,6 \%$ & 4,30 & $26,5 \%$ & 4,32 & $22,8 \%$ & 4,36 & $27,0 \%$ \\
\hline 6 & 4,39 & $7,5 \%$ & 4,46 & $10,4 \%$ & 4,54 & $12,4 \%$ & 4.57 & $10,4 \%$ & 4,55 & $10,5 \%$ & 4,39 & $8.7 \%$ & 4,35 & \begin{tabular}{|l|}
$9,7 \%$ \\
\end{tabular} & 4,46 & $12,3 \%$ & 4,39 & $11,5 \%$ & 4,51 & $11.9 \%$ \\
\hline 7 & 4,45 & $6.8 \%$ & 4,21 & $6,9 \%$ & 4,61 & $7,7 \%$ & 4,54 & $9,7 \%$ & 4,55 & $8,4 \%$ & 4,57 & $6,6 \%$ & 4,59 & $6,8 \%$ & 4,49 & $7,9 \%$ & 4,49 & $7,9 \%$ & 4,37 & $8,0 \%$ \\
\hline 8 & 4,58 & $4,5 \%$ & 4,25 & $4,3 \%$ & 4.63 & $4,9 \%$ & 4.65 & $5,6 \%$ & 4,52 & $5,1 \%$ & 4,46 & $4,3 \%$ & 4,54 & $4,9 \%$ & 4,54 & $5,4 \%$ & 4,55 & $6,4 \%$ & 4,64 & $5,9 \%$ \\
\hline 9 & 67 & $0,7 \%$ & 4 & $0,9 \%$ & 50 & $1.2 \%$ & 4,43 & $2,1 \%$ & 4,52 & $1.6 \%$ & 4,86 & $1,1 \%$ & 4,37 & $1.0 \%$ & 4,52 & $2,4 \%$ & .24 & $1,8 \%$ & 4,4 & $1.9 \%$ \\
\hline & & & & & & & & & 4,79 & $1,0 \%$ & 4,10 & $1,0 \%$ & 4,19 & $1,6 \%$ & 4,42 & $1,6 \%$ & 4,62 & $1,8 \%$ & 4,34 & $1,7 \%$ \\
\hline Total & 4,31 & 2.574 & 4,35 & 2.040 & 4,48 & 1.965 & 4.41 & 2.005 & 4,42 & 1.971 & 4.28 & 1.981 & 4,36 & 1.961 & 4,30 & 2.101 & 4,30 & 2.068 & 4,32 & 2.077 \\
\hline
\end{tabular}

Fuente: elaboración propia a partir de los estudios del CIS números 2632, 2700, 2749, 2914, 2960, $3001,3041,3114,3156$ y 3191.

En cuanto a la frecuencia de consumo de noticias audiovisuales, las variables sociodemográficas estudiadas no permiten establecer diferencias importantes. Es decir: todos los grupos las consumen muy frecuentemente independientemente del sexo, edad, hábitat, clase social, nivel de estudios o ideología. Esta situación apenas ha variado en la década estudiada. 
RLCS, Revista Latina de Comunicación Social, 77, 55-72

[Investigación] DOI: 10.4185/RLCS-2020-1449 | ISSN 1138-5820 | Año 2020

Tabla 6. Perfil sociodemográfico de los buscadores de noticias en Internet.

\begin{tabular}{|c|c|c|c|c|c|c|c|c|c|c|c|c|c|c|c|c|c|c|c|c|}
\hline & \multicolumn{2}{|c|}{2006} & \multicolumn{2}{|c|}{2007} & \multicolumn{2}{|c|}{2008} & \multicolumn{2}{|c|}{2011} & \multicolumn{2}{|c|}{2012} & \multicolumn{2}{|c|}{2013} & \multicolumn{2}{|c|}{2014} & \multicolumn{2}{|c|}{2015} & \multicolumn{2}{|c|}{2016} & \multicolumn{2}{|c|}{2017} \\
\hline Sexo & Media & $\mathrm{N}$ & Media & $\mathrm{N}$ & Media & $\mathrm{N}$ & Media & $\mathrm{N}$ & Media & $\mathrm{N}$ & Media & $\mathrm{N}$ & Media & $\mathrm{N}$ & Media & $\mathrm{N}$ & Media & $\mathrm{N}$ & Media & $\mathrm{N}$ \\
\hline Hombre & 1,65 & $49,8 \%$ & 1,75 & $48,8 \%$ & 1,76 & $48,9 \%$ & 2,09 & $49,2 \%$ & 2,29 & $49,0 \%$ & 2.29 & $49,0 \%$ & 2,36 & $48,8 \%$ & 2,34 & $48,3 \%$ & 2.56 & $48,4 \%$ & 2,76 & $48,4 \%$ \\
\hline Mujer & 1,44 & $30,2 \%$ & 1.53 & $51,2 \%$ & 1,55 & $51,1 \%$ & 1,74 & $50,8 \%$ & 1.99 & $51.0 \%$ & 1,95 & $51,0 \%$ & 2,08 & $51,2 \%$ & 2,03 & $51,7 \%$ & 2,19 & $51,6 \%$ & 2,46 & $51,6 \%$ \\
\hline Total & 1,55 & 3.191 & 1.64 & 2.455 & 1.65 & 2.477 & 1.91 & 2.472 & 2.14 & 2.484 & 2.12 & 2.485 & 2,22 & 2.480 & 2.18 & 2.493 & 2,37 & 2.491 & 2.6 & 2.487 \\
\hline Hábitat & Media & $\mathrm{N}$ & Modia & $\mathrm{N}$ & Media & $\mathrm{N}$ & Media & $\mathrm{N}$ & Media & $\mathrm{N}$ & Media & $\mathrm{N}$ & Media & $\mathrm{N}$ & Media & $\mathrm{N}$ & Media & $\mathrm{N}$ & Media & \\
\hline Rural & 1.49 & $53,8 \%$ & 1,56 & $48,6 \%$ & 1,51 & $47,5 \%$ & 1,71 & $47,3 \%$ & 1,96 & $47.6 \%$ & 1,90 & $47,3 \%$ & 1.95 & $47,1 \%$ & 1,98 & $48,6 \%$ & 2,13 & $48.2 \%$ & 2,44 & $48,9 \%$ \\
\hline Urbano & 1.62 & $46.2 \%$ & 1,72 & $51.4 \%$ & 1.78 & $52.5 \%$ & 2.09 & $52,7 \%$ & 2,30 & $52.4 \%$ & 2.32 & $52.7 \%$ & 2,46 & $52.9 \%$ & 2,37 & $51,4 \%$ & 2.59 & $51,8 \%$ & 2,76 & $51.1 \%$ \\
\hline Total & 1,55 & 3.191 & 1,64 & 2.455 & 1,65 & 2.477 & 1,91 & 2.472 & 2,14 & 2.484 & 2,12 & 2.485 & 2,22 & 2.480 & 2,18 & 2.493 & 2,37 & 2.491 & 2.6 & 2.487 \\
\hline Edad & Media & $\mathrm{N}$ & Media & $\mathrm{N}$ & Media & $\mathrm{N}$ & Media & $\mathrm{N}$ & Media & $\mathrm{N}$ & Media & $\mathrm{N}$ & Media & $\mathrm{N}$ & Media & $\mathrm{N}$ & Media & $\mathrm{N}$ & Media & \\
\hline Menos de 34 & 1,69 & $53,5 \%$ & 1,85 & $31,4 \%$ & 2,02 & $30.9 \%$ & 2,30 & $29.7 \%$ & 2,58 & $28.2 \%$ & 2.51 & $28,0 \%$ & 2,58 & $25,4 \%$ & 2.62 & $22,7 \%$ & 2,78 & $22.4 \%$ & 3,21 & $21.9 \%$ \\
\hline De 35 a 49 & 1,55 & $18,5 \%$ & 1,86 & $27,7 \%$ & 1.63 & $27,9 \%$ & 2,11 & $28,0 \%$ & 2,44 & $29,3 \%$ & 2,43 & $29,1 \%$ & 2,53 & $30.0 \%$ & 2,46 & $29,0 \%$ & 2,68 & $29,3 \%$ & & $28,9 \%$ \\
\hline De 50 a 64 & 1,33 & $14,0 \%$ & 1,47 & $20,6 \%$ & 1.53 & $21,0 \%$ & 1.72 & $22,3 \%$ & 1,85 & $22.3 \%$ & 1,97 & $22,3 \%$ & 2.09 & $23,5 \%$ & 2.12 & $24,7 \%$ & 2,37 & $24,1 \%$ & 2,63 & $24,9 \%$ \\
\hline $65 \mathrm{y}$ mís & 1,22 & $14,0 \%$ & 1,2 & $20,3 \%$ & 1.25 & $20.2 \%$ & 1,27 & $19,9 \%$ & 1,41 & $20.2 \%$ & 1,32 & $20,6 \%$ & 1,49 & $21,1 \%$ & 1,48 & $23,5 \%$ & 1,62 & $24,2 \%$ & 1,57 & $24,4 \%$ \\
\hline Total & 1.55 & 3.191 & 1,64 & 2.455 & 1.65 & 2.477 & 1,91 & 2.472 & 2,14 & 2.484 & 2.12 & 2.485 & 2.22 & 2.480 & 2.18 & 2.493 & 2,37 & 2.491 & 2.6 & 2.487 \\
\hline \begin{tabular}{|l} 
Estatus socioeconómico \\
\end{tabular} & Media & $\mathrm{N}$ & Media & $\mathrm{N}$ & Media & $\mathrm{N}$ & Media & $\mathrm{N}$ & Media & $\mathrm{N}$ & Media & $\mathrm{N}$ & Media & $\mathrm{N}$ & Media & $\mathrm{N}$ & Media & $\mathrm{N}$ & Media & $\mathrm{N}$ \\
\hline Clase alta/media alta & 2,06 & $15,9 \%$ & 2,25 & $17,0 \%$ & 2,41 & $16,8 \%$ & 2,86 & $16,0 \%$ & 3,13 & $18,4 \%$ & 3,12 & $17,4 \%$ & 3,10 & $17,2 \%$ & 3,09 & $18,8 \%$ & 3,39 & $19,0 \%$ & 3,49 & $20,2 \%$ \\
\hline Nuevas clases medias & 1.64 & $19.0 \%$ & 1,74 & $21.1 \%$ & 1.75 & $19,9 \%$ & 2.08 & $21,5 \%$ & 2,38 & $21.8 \%$ & 2.45 & $23,5 \%$ & 2.44 & $24,8 \%$ & 2,42 & $25,0 \%$ & 2.65 & $23,0 \%$ & 2,89 & $23.5 \%$ \\
\hline Viejas clases medias & 1,45 & $12,6 \%$ & 1,43 & $17,7 \%$ & 1,48 & $18,4 \%$ & 1,58 & $16,1 \%$ & 1,73 & $15,1 \%$ & 1.90 & $12,8 \%$ & 1.96 & $11,7 \%$ & 1,90 & $13,6 \%$ & 1,98 & $14,2 \%$ & 2,32 & $14,5 \%$ \\
\hline Obreros cualificados & 1,41 & $34,4 \%$ & 1,39 & $31,4 \%$ & 1,39 & $33,1 \%$ & 1,65 & $33,1 \%$ & 1.82 & $31,3 \%$ & 1,62 & $33,1 \%$ & 1.82 & $32,1 \%$ & 1,81 & $28.9 \%$ & 1.94 & $29,3 \%$ & 2,15 & $27,3 \%$ \\
\hline Obreros no cualificados & 1,34 & $18,1 \%$ & 1.52 & $12,8 \%$ & 1,39 & $11,8 \%$ & 1.52 & $13,3 \%$ & 1,52 & $13,5 \%$ & 1,67 & $13,2 \%$ & 1,84 & $14.2 \%$ & 1.55 & $13,8 \%$ & 1.77 & $14,5 \%$ & 2,05 & $14,5 \%$ \\
\hline Total & 1,55 & 3.092 & 1,64 & 2.364 & 1,65 & 2.434 & 1,91 & 2.430 & 2,14 & 2.445 & 2,12 & 2.447 & 2,22 & 2.427 & 2,18 & 2.428 & 2,37 & 2.442 & 2.6 & 2.438 \\
\hline Nivel de estudios & Media & $\mathrm{N}$ & Media & $\mathrm{N}$ & Media & $\mathrm{N}$ & Media & $\mathrm{N}$ & Media & $\mathrm{N}$ & Media & $\mathrm{N}$ & Media & $\mathrm{N}$ & Media & $\mathrm{N}$ & Media & $\mathrm{N}$ & Media & $\mathrm{N}$ \\
\hline Sin estudios & 1,12 & $8,1 \%$ & 1,08 & $9,2 \%$ & 1,23 & $8,0 \%$ & 1,15 & $7,0 \%$ & 1.24 & $6.5 \%$ & 1.14 & $6,0 \%$ & 1,24 & $5,6 \%$ & 1,15 & $5,5 \%$ & 1,15 & $4,7 \%$ & 1,16 & $5.2 \%$ \\
\hline Primaria & 1.29 & $43,1 \%$ & 1,33 & $45,2 \%$ & 1,26 & $44,1 \%$ & 1,43 & $44,4 \%$ & 1,53 & $45,3 \%$ & 1,32 & $19,6 \%$ & 1,43 & $20,3 \%$ & 1,41 & $18,0 \%$ & 1,29 & $18,1 \%$ & 1,48 & $18,5 \%$ \\
\hline Secundaria & 1.73 & $14,9 \%$ & 1.9 & $11.8 \%$ & 1,98 & $13,1 \%$ & 2.25 & $13,9 \%$ & 2,63 & $11,8 \%$ & 2.01 & $38,6 \%$ & 2.17 & $38.5 \%$ & 2.07 & $36,6 \%$ & 2,32 & $37,1 \%$ & 2,59 & $35,7 \%$ \\
\hline F.P & 1,64 & $17,0 \%$ & 1,76 & $15,8 \%$ & 1,67 & $16,8 \%$ & 2,06 & $17,5 \%$ & 2,37 & $16.8 \%$ & 2,36 & $16,9 \%$ & 2.43 & $17,0 \%$ & 2.23 & $19.2 \%$ & 2,54 & $19.1 \%$ & 2.99 & $18,8 \%$ \\
\hline Medios universitarios & 2,03 & $8.2 \%$ & 1,98 & $7,8 \%$ & 2,38 & $8,4 \%$ & 2,82 & $6,9 \%$ & 3.05 & $8.0 \%$ & & & & & & & & & & \\
\hline Superiores & 2,3 & $8,4 \%$ & 2,71 & $10,2 \%$ & 2.69 & $9,6 \%$ & 3,17 & $10,3 \%$ & 3,57 & $11,6 \%$ & 3,25 & $18,8 \%$ & 3,30 & $18.6 \%$ & 3.28 & $20,6 \%$ & 3,51 & $21,1 \%$ & 3,6 & $21,9 \%$ \\
\hline Total & 1,55 & 3.191 & 1,64 & 2.455 & 1.65 & 2.474 & 1,91 & 2.461 & 2,14 & 2,477 & 2,12 & 2.479 & 2.22 & 2.478 & 2,18 & 2.491 & 2,37 & 2.485 & 2.6 & 2.485 \\
\hline Ideologia & Media & $\mathrm{N}$ & Media & $\mathrm{N}$ & Media & $\mathrm{N}$ & Media & $\mathrm{N}$ & Media & $\mathrm{N}$ & Media & $\mathrm{N}$ & Media & $\mathrm{N}$ & Media & $\mathrm{N}$ & Media & $\mathrm{N}$ & Media & $\mathrm{N}$ \\
\hline 1 (lzquierda) & 1,89 & $7,3 \%$ & 1,83 & $4,3 \%$ & 1,93 & $4,4 \%$ & 2,48 & $4,4 \%$ & 2,88 & $4,9 \%$ & 2,93 & $4,8 \%$ & 3,15 & $6.6 \%$ & 2.89 & $5.3 \%$ & 3,08 & $6.6 \%$ & 3.35 & $4,7 \%$ \\
\hline 2 & 1.73 & $10,7 \%$ & 2,2 & $5,4 \%$ & 2,09 & $5,2 \%$ & 2,53 & $6,1 \%$ & 2,68 & $4.9 \%$ & 2,60 & $6,8 \%$ & 2.98 & $8.0 \%$ & 2,93 & $5,1 \%$ & 3,02 & $6,7 \%$ & 3,49 & $5,7 \%$ \\
\hline 3 & 1.62 & $16,9 \%$ & 1.75 & $17,5 \%$ & 1,96 & $16,0 \%$ & 2.21 & $15,9 \%$ & 2,23 & $19.9 \%$ & 2,37 & $19.7 \%$ & 2,53 & $20,3 \%$ & 2,52 & $17,8 \%$ & 2.79 & $18.9 \%$ & 3,02 & $17,0 \%$ \\
\hline 4 & 1,41 & $15.5 \%$ & 1,59 & $19,9 \%$ & 1,64 & $18,6 \%$ & 1,83 & $15,6 \%$ & 2,15 & $18,1 \%$ & 2.28 & $17,2 \%$ & 2.16 & $18,6 \%$ & 2.24 & $15,7 \%$ & 2,37 & $15,6 \%$ & 2.65 & $16,1 \%$ \\
\hline 5 & 1,56 & $28,8 \%$ & 1,64 & $28,7 \%$ & 1.62 & $27,7 \%$ & 1,90 & $28,2 \%$ & 2,18 & $25.8 \%$ & 1,99 & $29.8 \%$ & 2.15 & $22.6 \%$ & 2,13 & $26,5 \%$ & 2.25 & $22,8 \%$ & 2,62 & $27,0 \%$ \\
\hline 6 & 1.77 & $7,5 \%$ & 1,61 & $10,4 \%$ & 1.55 & $12,4 \%$ & 1.96 & $10,4 \%$ & 2.46 & $10,5 \%$ & 2.17 & $8,7 \%$ & 2.03 & $9,7 \%$ & 2.29 & $12.3 \%$ & 2.57 & $11.5 \%$ & 2.61 & $11.9 \%$ \\
\hline 7 & 1.75 & $6,8 \%$ & 1,65 & $6,9 \%$ & 1,79 & $7,7 \%$ & 1,98 & \begin{tabular}{|l|}
$9,7 \%$ \\
\end{tabular} & 2,14 & $8,4 \%$ & 2,11 & $6,6 \%$ & 2.25 & $6.8 \%$ & 2,16 & $7,9 \%$ & 2,28 & $7,9 \%$ & 2,72 & $8,0 \%$ \\
\hline 8 & 1.62 & $4,5 \%$ & 1.85 & $4,3 \%$ & 1,70 & $4,9 \%$ & 1,69 & $5,6 \%$ & 2,05 & $5,1 \%$ & 1.71 & $4,3 \%$ & 2,11 & $4,9 \%$ & 1,93 & $5.4 \%$ & 2,30 & $6.4 \%$ & 2,84 & $5,9 \%$ \\
\hline 9 & 2.5 & $0,7 \%$ & 1,83 & $0,9 \%$ & 1,75 & $1,2 \%$ & 1,93 & $2,1 \%$ & 1,61 & $1.6 \%$ & 2.29 & $1,1 \%$ & 1.74 & $1,0 \%$ & 1,86 & $2,4 \%$ & 1.84 & $1,8 \%$ & 1,79 & $1,9 \%$ \\
\hline 10 (Derecha) & 1,38 & $1,2 \%$ & 1,61 & $1,6 \%$ & 1,58 & $1,8 \%$ & 1,29 & $1,9 \%$ & 1,95 & $1,0 \%$ & 2,20 & $1,0 \%$ & 2.68 & $1.6 \%$ & 2,03 & $1.6 \%$ & 2,38 & $1.8 \%$ & 2,23 & $1,7 \%$ \\
\hline Total & 1,55 & 2.574 & 1,64 & 2.040 & 1.65 & 1.965 & 1.91 & 2.005 & 2,14 & 1.971 & 2.12 & 1.981 & 2,22 & 1.961 & 2.18 & 2.101 & 2,37 & 2.068 & 2.6 & 2.077 \\
\hline
\end{tabular}

Fuente: elaboración propia a partir de los estudios del CIS números 2632, 2700, 2749, 2914, 2960, $3001,3041,3114,3156$ y 3191.

En la búsqueda de noticias políticas o sociales en Internet, los hombres y los habitantes en núcleos urbanos lo hacen algo más frecuentemente. En cuanto a la edad, la relación es inversa: a mayor edad, menor búsqueda de noticias digitales. En la clase social, cuanto más alta, más frecuente el consumo. Lo mismo ocurre con el nivel educativo. En general, la frecuencia de búsqueda de noticias en Internet ha aumentado en torno al doble. Esto sólo no ha ocurrido entre las personas sin estudios o solo con estudios primarios.

\subsection{Predictores del consumo de noticias}

Tabla 7. Predictores de lectura de secciones políticas en periódicos.

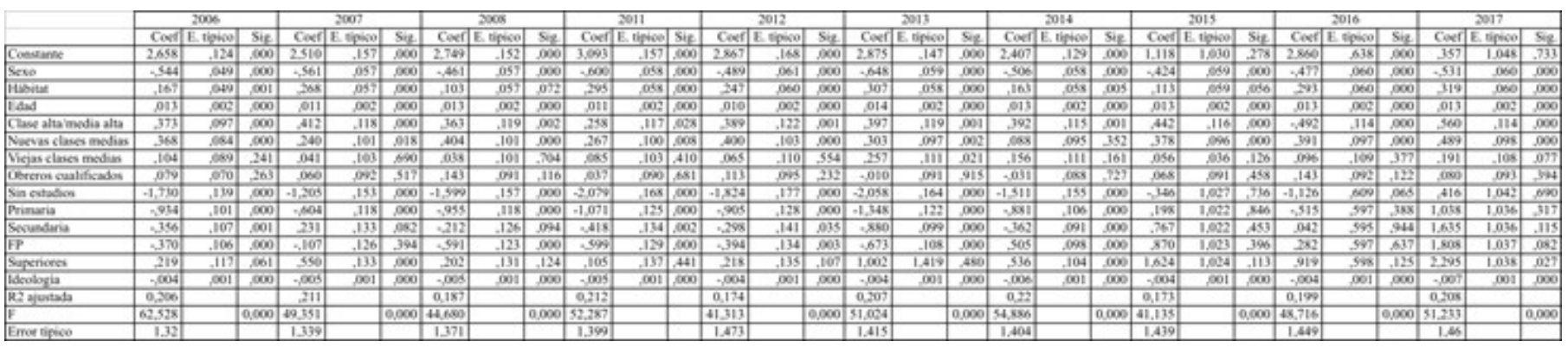

Fuente: elaboración propia a partir de los estudios del CIS números 2632, 2700, 2749, 2914, 2960, $3001,3041,3114,3156$ y 3191. 
RLCS, Revista Latina de Comunicación Social, 77, 55-72

[Investigación] DOI: 10.4185/RLCS-2020-1449 | ISSN 1138-5820 | Año 2020

La R2 ajustada indica cuánto predicen las seis variables independientes elegidas la variable dependiente. El sexo, hábitat, edad, clase social, nivel de estudios e ideología son capaces de explicar entre el 17 y el 22 por ciento de la lectura de prensa según los años.

Las variables con capacidad predictiva son aquellas cuya significatividad es menor de 0,05 . Según los resultados se excluyen las variables siguientes: viejas clases medias y obreros cualificados (en todos los diez años), estudios superiores (en ocho años) y con estudios secundarios (en seis años). Asimismo hay que tomar con cautela las variables: con estudios de FP (en cuatro años), sin estudios (en tres años), con estudios primarios (en tres años), hábitat (en tres años), nueva clases medias (en tres años) y clase alta (en un año).

Los mejores predictores del consumo de noticias políticas en prensa son estar sin estudios, con estudios primarios, con FP, sexo (todas ellas negativas) y clase alta/media alta y nuevas clases medias (en positivo). Dicho de otro modo, a menos estudios, menor lectura de prensa, al igual que ocurre con las mujeres. Y a clase social más alta, más consumo de noticias en periódicos.

Tabla 8. Predictores de consumo de noticias en radio o televisión.

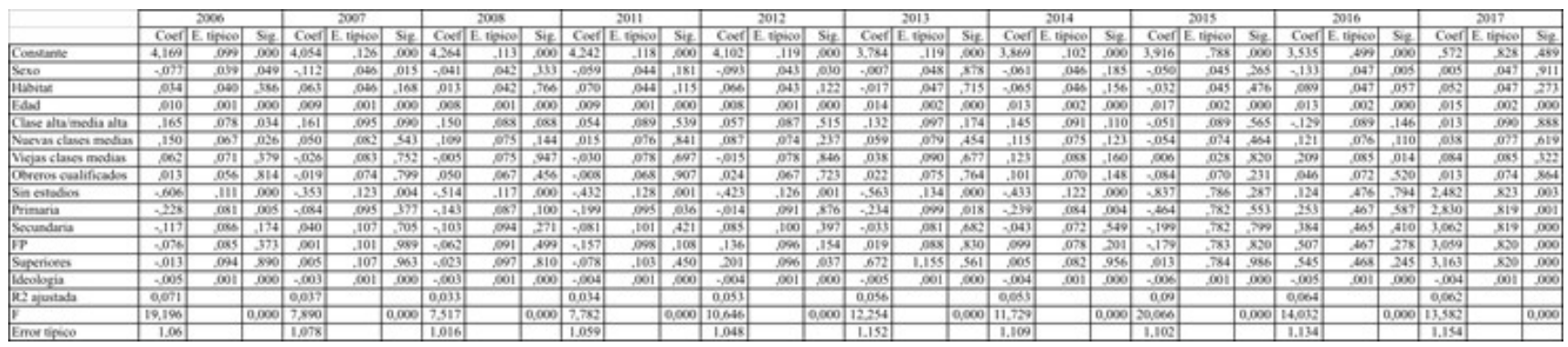

Fuente: elaboración propia a partir de los estudios del CIS números 2632, 2700, 2749, 2914, 2960, $3001,3041,3114,3156$ y 3191.

En cuanto a la información audiovisual, la R2 indica que las variables elegidas sólo son capaces de explicar entre el 3 y 9 por ciento del consumo. La mayor parte de las variables no son significativas. Sólo presentan un alto coeficiente negativo estar sin estudios y un bajo coeficiente positivo la edad. Esto es: a menos estudios, menor consumo de noticias en radio y televisión. Y a más edad, más visionado de informativos.

Tabla 9. Predictores de búsqueda de información política o social en Internet.

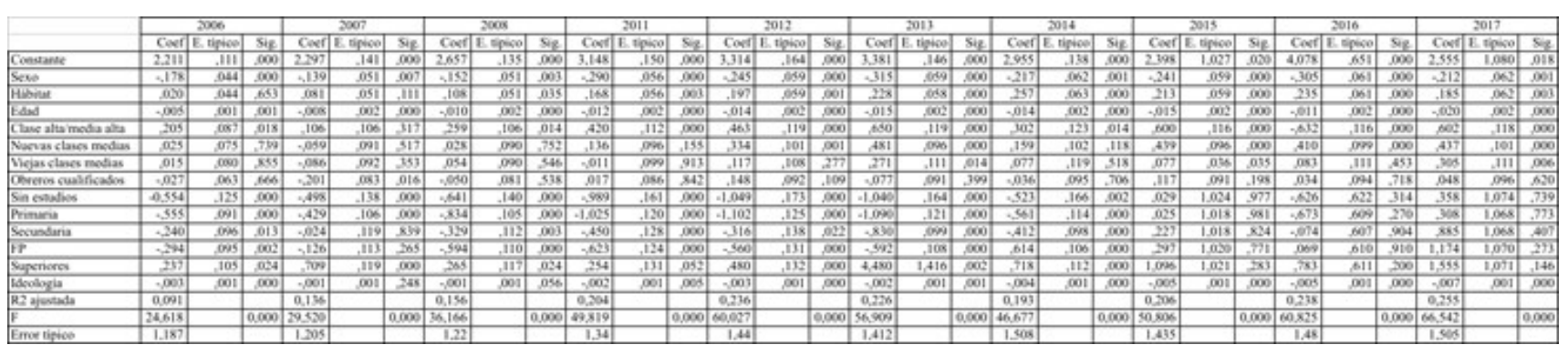

Fuente: elaboración propia a partir de los estudios del CIS números 2632, 2700, 2749, 2914, 2960, $3001,3041,3114,3156$ y 3191. 
En cuanto a la búsqueda de información en Internet, la R2 indica que las variables elegidas explican entre el 9 y el 25 por ciento del consumo, con una tendencia claramente ascendente. Sin embargo han de ser descartadas algunas variables por no ser significativas en la mayor parte de los años. En concreto: todas las de estatus socioeconómico excepto la clase social alta/media alta y todas las de nivel de estudios excepto estar sin estudios, sólo con estudios primarios o con FP.

Los predictores más eficientes del consumo de noticias en Internet son estar sin estudios, sólo con estudios primarios o con FP, los tres con coeficientes negativos. Aunque hay que notar que en los tres últimos años estudiados, las cifras no son significativas. También el sexo presenta coeficientes negativos y significativos en todos los años menos uno. Y la clase social alta/media alta arroja altos coeficientes positivos, sobre todo en los últimos años. Esto quiere decir que a menos estudios, menor búsqueda de información en Internet. Las mujeres también usan menos la red para este fin. Y finalmente, a clase social más alta, más consumo de noticias digitales.

\subsection{Correlaciones entre el consumo de noticias en diferentes medios}

Tabla 10. Coeficiente de Pearson de correlaciones entre los distintos medios.

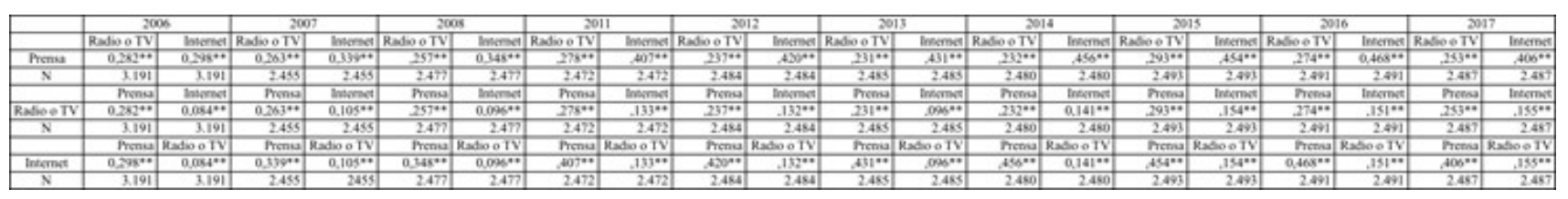

Fuente: elaboración propia a partir de los estudios del CIS números 2632, 2700, 2749, 2914, 2960, $3001,3041,3114,3156$ y 3191.

En cuanto a las correlaciones de consumo entre los tres sectores mediáticos, se presentan varias situaciones. El coeficiente de correlación de Pearson alcanza valores de -1 a 1 . Cuando el coeficiente de correlación de Pearson entre 0,7 y 1 , la relación es fuerte y directa. Cuando está entre $-0,1$ y 0,1, la relación es muy débil y si es 0 es que no existe relación entre las variables. Cuando está entre $-0,7$ y 1, la relación entre las dos variables analizadas es fuerte e inversa. Esto no implica causalidad, sólo relaciones lineales entre dos variables.

En estos datos, los coeficientes de correlación son significativos e indican que los ciudadanos se informan a través de diferentes medios. Sin embargo, son coeficientes no muy altos. Los consumidores de prensa son los que presentan coeficientes de correlación más altos con el resto de medios, tanto radio o televisión (siempre en el entorno de 0,2) como sobre todo Internet (entre 0,2 y $0,4)$. La tendencia es a aumentar a través de los años. De este modo, la correlación entre el consumo de noticias prensa e Internet es la más alta de toda la serie de datos, aunque de nivel medio.

\section{Discusión}

En Meilán (2010) los lectores diarios de prensa entre 2002 y 2004 habían bajado de manera importante (37 por ciento), pero a partir de ahí se habían mantenido estables. Esto se mantiene así hasta 2010, pero en 2011 sube el número de los lectores diarios, aunque bajan los que lo hacen con menor frecuencia. De este modo, las personas que nunca leen sobre política en los periódicos es siempre de alrededor de un tercio, lo que se mantiene bastante estable entre 2000 y 2017 . Por otro lado, la información en radio y televisión también es el medio dominante ahora, con alrededor de dos tercios de los encuestados que declaran consumirla todos o casi todos los días. En los periodos 20002009 y 2006-2017 las cifras son por tanto muy similares. Finalmente, la lectura en Internet todos los 
días había subido entre 2004 y 2009 del 3 al 11 por ciento. Este ritmo de crecimiento sostenido se mantiene hasta alcanzar el 25 por ciento en 2017.

Meilán (2010) sugiere que las oscilaciones en el consumo de medios pueden deberse a los diferentes niveles de interés informativo en los diversos años. Sin embargo las evidencias para el caso español son débiles. Más bien habría que encontrar las explicaciones en los cambios tecnológicos. Desde este punto de vista, la prensa, radio y televisión sufren cambios más lentos, así como su consumo. En televisión se produce un aumento de canales entre 2006 y 2017, pero el consumo no sube. En prensa, los únicos cambios importantes fueron los periódicos gratuitos, pero tuvieron un auge muy breve y no afectaron de manera importante al consumo general. Sin embargo, la mayor penetración progresiva de Internet en los hogares de los españoles se hace notar también en su búsqueda de información política y social a través de este medio de manera muy destacada.

En cuanto al perfil sociodemográfico del consumo de noticias en los diferentes medios, en el periodo 2000-2008 los lectores de prensa eran más masculinos, con mayor consumo entre bachilleres y universitarios y entre los 35 y los 49 años, mientras que los mayores de 65 estaban muy por debajo de la media. Asimismo las categorías de clase social alta leían la prensa más que la media. Todos estos vectores se confirman también entre 2006 y 2017, aunque se aumenta la base de lectores por encima de la media entre los 35 y los 64 años.

Los datos de radio y televisión solo se presentan conjuntamente en Meilán (2010) entre 2006 y 2009, por lo que no es posible establecer comparaciones pertinentes con el periodo completo de este estudio (2006-2017), que ya incluye aquellos años. En el caso de Internet, la investigación anterior afirmaba que era el medio donde las fronteras sociodemográficas eran más nítidas. Entre 2004 y 2009 hombres, bachilleres, universitario y menores de 35 declaraban buscar más información en la red que la media de la población. La edad era la variable clave, con un mayor consumo del grupo de edad entre 18 y 34 años y mucho menor en mayores de 65. Lo mismo ocurría con las dos clases sociales más altas. Los datos entre 2006 y 2017 ahondan estas tendencias. Efectivamente los hombres utilizan más la red para informarse que las mujeres. La edad se ensancha ahora para establecer una relación totalmente inversa en los grupos: a mayor edad, menor búsqueda de noticias. Lo mismo ocurre con la clase social y el nivel educativo, donde la relación es directa. La gran diferencia es que las frecuencias de consumo han aumentado el doble entre 2006 y 2017, aun descontando que eso no ocurre entre las personas sin estudios o sólo con estudios primarios.

En general, el consumo de noticias políticas en grandes ciudades era siempre superior en los tres medios, aunque en radio y televisión las diferencias eran menores. De este modo, la brecha rural era patente en prensa e Internet pero no así en información audiovisual. La autoubicación ideológica no presentaba diferencias importantes, aunque había un ligero aumento de lectura de prensa e Internet entre los ciudadanos más a la izquierda y de la radio o televisión entre las personas más a la derecha. Entre 2006 y 2017 se confirman estas tendencias.

En conclusión, el estudio de Meilán (2010) hablaba de marcadas desigualdades sociodemográficas en el consumo de noticias. Los hombres, personas de edad intermedia, con niveles educativos medios y altos y residentes en núcleos urbanos presentaban un mayor acceso a la información. Mientras que las mujeres, personas de clase baja y con bajos niveles educativos declaraban un consumo informativo menor. Las diferencias eran más marcadas en prensa e Internet que en radio y televisión, lo que sugería un diferencial de acceso a los diferentes medios. Estas conclusiones siguen siendo válidas para el periodo 2006-2017. 
Los predictores explicaban en 2010 entre el 23 y 38 del consumo de noticias en prensa. En esta investigación solo alcanzan entre el 17 y el 22 por ciento, ya que ahora se han excluido las variables de situación laboral, interés en política y consumo de otros medios. Entonces se demostraba que a mayor edad y nivel educativo, mayor consumo. Las mujeres y clases sociales más bajas leían menos periódicos. La edad y el hábitat en núcleos urbanos se destapaban como tendencia emergente. En el periodo 2006-2017 son buenos predictores las clases medias y altas (en positivo), los bajos niveles de estudios y el sexo femenino (en negativo). Sin embargo la influencia de las variables edad, hábitat e ideología parece no ser relevante.

Con respecto a la información en radio o televisión, entre 2006 y 2009 las variables explicaban sólo entre el 4 y 8 por ciento del consumo y entre 2006 y 2017 las cifras son similares (entre el 3 y el 9 por ciento). Entonces sólo la edad era un factor explicativo positivo, aunque con un bajo coeficiente. Esta variable vuelve a presentarse de igual modo. La novedad ahora es que estar sin estudios presenta un alto coeficiente negativo. Es decir: a mayor edad, mayor consumo de informativos; y a menos estudios, menor interés en la noticias de radio y televisión. El modelo no funciona adecuadamente para estos medios.

En cuanto a la búsqueda de información política y social en Internet, entre 2004 y 2009 las variables predecían entre el 14 y el 21 por ciento del consumo. Entre 2006 y 2017 se mueven entre el 9 y el 25 por ciento, con una tendencia al alza. Esto es: las variables sociodemográficas explican cada vez más el consumo de noticias digitales. En el primer estudio, todas las categorías de clase social predecían un consumo inferior a la media. Y la edad y nivel educativo era predictores positivos, así como el sexo femenino. Entre 2006 y 2017 los predictores más eficientes son estar sin estudios, con estudios primarios o FP (en negativo), la clase social alta/media alta y el sexo femenino. Esto es: a menos estudios, menor búsqueda en Internet; a mayor clase social, más búsqueda; y las mujeres tienden a consumir menos noticias digitales que los hombres.

Finalmente, el cruce de las variables de consumo entre los tres grupos de medios demostraba una alta correlación entre 2000 y 2009. Por tanto, a mayor consumo de noticias en prensa, radio, televisión o Internet le correspondía un mayor consumo en cualquiera de los demás medios y al revés como el consumo era menor. Los coeficientes más altos los arrojaba la prensa con el resto de medios. Estas correlaciones se confirman plenamente con parecidos indicadores entre 2006 y 2017.

\section{Conclusiones}

El problema de estudio de este artículo parte de la relativa discrepancia en la literatura sobre cómo Internet ha afectado al consumo de noticias en los medios tradicionales y la posible validez o no de los criterios sociodemográficos como predictores de ese consumo informativo. A continuación se exponen de manera somera las principales conclusiones de esta contribución a partir de las hipótesis planteadas con anterioridad.

PI1) ¿Internet ha supuesto un cambio significativo en los niveles de consumo de noticias en los medios tradicionales?

Los lectores diarios de periódicos han aumentado desde el 16 al 23 por ciento, contando tanto con publicaciones impresas como digitales. En el caso de la radio y la televisión, su consumo informativo diario se ha mantenido estable en torno al 67 por ciento. Es el propio medio Internet el que ha experimentado un gran aumento, del 4 al 25 por ciento de ciudadanos que lo consultan diariamente para buscar noticias. Así que el cambio ha sido al alza tanto para los periódicos digitales como para la búsqueda de información política o social en Internet. 
Pero por otro lado, el dato de los excluidos ha cambiado muy levente. El porcentaje de personas que no leen prensa se ha mantenido estable a lo largo de la década en torno al 36 y 38 por ciento, los que nunca se informan por radio o televisión van del 3 al 6 por ciento y solamente los que nunca buscan noticias por Internet se ha reducido del 78 al 46 por ciento.

PI2) ¿La composición sociodemográfica de los consumidores de noticias es muy distinta dependiendo del medio de que se trate?

Los datos demuestran que el consumo de noticias en radio y televisión están tan generalizado que las variables sociodemográficas elegidas no permiten establecer diferencias apreciables. Sin embargo, en el caso de los lectores de periódicos, son más masculinos, más urbanos, de edades intermedias (3564), de clases medias y altas y con mayor nivel formativo que la media de la población. Los usuarios de noticias en Internet coinciden básicamente con el perfil anterior excepto en la edad, ya que su público es más joven que la media. De modo que cabe establecer dos grandes grupos de ciudadanos: los que consumen información por radio y televisión, que son similares a la media del país; y los que leen noticias en periódicos e Internet, que presentan rasgos distintos a la media pero comunes entre sí excepto por la edad.

PI3) ¿Las variables sociodemográficas siguen siendo buenos predictores del consumo de noticias?

Las seis variables elegidas (incluyendo autoubicación ideológica) son capaces de explicar entre el 17 y el 22 por ciento del consumo de prensa, entre el 3 y el 9 por ciento del consumo audiovisual y entre el 9 y el 25 por ciento de la búsqueda por Internet, dependiendo de los años. Por tanto su capacidad predictiva del consumo de información audiovisual es muy baja. En el caso de los periódicos e Internet, las variables que predicen más eficientemente su consumo son el nivel de estudios y el sexo femenino (en negativo) y la clase social (en positivo). Por tanto tres de seis variables elegidas en dos de los tres medios estudiados pueden considerarse buenos predictores.

PI4) ¿El consumo de noticias en un medio predice significativamente el consumo en los demás medios?

Los coeficientes de correlación entre el consumo de noticias en los tres medios son significativos, aunque es cierto que no son muy altos. Los ciudadanos que leen periódicos presentan los coeficientes más altos con los otros dos medios.

Estos resultados pueden considerarse satisfactorios pero no ocultan algunas limitaciones del estudio. Las opciones de pregunta y respuesta en el cuestionario podrían haberse formulado de manera más clara para los entrevistados, en concreto la necesaria aclaración sobre información política o general y la conveniente separación de medios impresos, digitales, radio y televisión. Esto no ha sido posible ejecutarlo en este artículo por la información secundaria disponible. Además podrían haberse manejado otras muchas variables tanto sociodemográficas como psicográficas y de otra índole. Pero los propios estudios del CIS, como es lógico, introducen sus propios criterios de extensión del cuestionario. Finalmente, los estudios de audiencia y recepción en general siguen necesitando investigación primaria e intermedios que preste más atención al tiempo como unidad de medida de cualquier acto de consumo de medios. Cuando la investigación académica y comercial sea capaz de recabar este tipo de datos, se podrían abrir nuevas e interesantes líneas de investigación en torno al consumo de contenidos de información, entretenimiento y marketing en los medios de comunicación. 


\section{Referencias}

Abernathy, P. M. (2018). The expanding news desert. Center for Innovation and Sustainability in Local Media. University of North Carolina at Chapel Hill. https://www.cislm.org/wpcontent/uploads/2018/10/The-Expanding-News-Desert-10 14-Web.pdf

Asociación para la Investigación de los Medios de Comunicación (AIMC) (2018). Resumen general del Estudio General de Medios (EGM): año móvil febrero a noviembre 2018. Madrid.

Bachmann, I., K. Kaufhold, S. Lewis, \& Gil de Zúñiga, H. (2010). News Platform Preference: Advancing the Effects of Age and Media Consumption on Political Participation. International Journal of Internet Science, 5(1), 34-47.

Boczkowski, P. J. (2010). The consumption of online news at work: making sense of emerging phenomena and rethinking existing concepts. Information, Communication \& Society, 13(4), 470484. https://doi.org/10.1080/13691181003639841

Casero-Ripollés, A. (2012). Beyond Newspapers: News Consumption among Young People in the Digital Era. Comunicar, 20(39), 151-158. https://doi.org/10.3916/C39-2012-03-05

Chan, J., \& Suen, W. (2008). A Spatial Theory of News Consumption and Electoral Competition. The Review of Economic Studies, 75(3), 699-728.

D'Haenens, L., Jankowski, N., \& Heuvelman, A. (2004). News in online and print newspapers: differences in reader consumption and recall. New Media \& Society, 6(3), 363-382. https://doi.org/10.1177/1461444804042520

Diddi, A., \& LaRose, R. (2006). Getting Hooked on News: Uses and Gratifications and the Formation of News Habits Among College Students in an Internet Environment. Journal of Broadcasting \& Electronic Media, 50(2), 193-210.

Goyanes, M., Artero, J. P., \& Zapata, L. (2018). The effects of news authorship, exclusiveness and media type in readers' paying intent for online news: An experimental study. Journalism. https://doi.org/10.1177/1464884918820741

Huang, E. (2009). The Causes of Youths' Low News Consumption and Strategies for Making Youths Happy News Consumers. Convergence: The International Journal of Research into New Media Technologies, 15(1), 105-122. https://doi.org/10.1177/1354856508097021

Ksiazek, T. B., Malthouse, E. C., \& Webster, J. G. (2010). News-seekers and Avoiders: Exploring Patterns of Total News Consumption Across Media and the Relationship to Civic Participation. Journal of Broadcasting \& Electronic Media, 54(4), 551-568. https://doi.org/10.1080/08838151.2010.519808

Livingstone, S., \& Markham, T. (2008). The Contribution of Media Consumption to Civic Participation. The British Journal of Sociology, 59(2), 351-371.

Manfredi Sánchez, J. L., Rojas Torrijos, J. L. y Herranz de la Casa, J. M. (2015). Periodismo emprendedor: el periodismo deportivo en España. Revista Latina de Comunicación Social, (70), 69-90. https://doi.org/10.4185/RLCS-2015-1035 
Meilán, X. (2010). Causas y consecuencias del consumo de información política en España (20002009). Colección Opiniones y Actitudes, 68. Centro de Investigaciones Sociológicas.

Mitchelstein, E., \& Boczkowski, P. J. (2010). Online News Consumption Research: An Assessment of Past Work and an Agenda for the Future. New Media \& Society, 12(7), 1085-1102. https://doi.org/10.1177/1461444809350193

Napoli, P., Weber, M., McCollough, K., \& Wang, Q. (2018). Assessing Local Journalism: News Deserts, Journalism Divides, and the Determinants of the Robustness of Local News. DeWitt Wallace Center for Media and Democracy, Duke University. https://dewitt.sanford.duke.edu/wpcontent/uploads/2018/08/Assessing-Local-Journalism_100-Communities.pdf

Obeholzer-Gee, F., \& Waldfogel, J. (2006). Media Markets and Localism: Does Local News en Español Boost Hispanic Voter Turnout? National Bureau of Economic Research Working Paper 12317. https://www.nber.org/papers/w12317.pdf

Pentina, I., \& Tarafdar, M. (2014). From "information"' to "knowing': Exploring the role of social media in contemporary news consumption”. Computers in Human Behavior, (35), 211-223. http://dx.doi.org/10.1016/j.chb.2014.02.045

Peters, C. (2012). Journalism to go. Journalism Studies, 13(5-6), 695-705. http://dx.doi.org/10.1080/1461670X.2012.662405

Van Cauwenberge, A., d'Haenens, L. \& Beentjes, H. (2010). Emerging Consumption Patterns among Young People of Traditional and Internet News Platforms in the Low Countries. Observatorio (OBS*) Journal, 4(3), 335-352.

Van Damme, K., Courtois, C., Verbrugge, K., \& De Marez, L. (2015). What's APPening to news? A mixed-method audience centred study on mobile news consumption. Mobile Media \& Communication, 3(2), 196-213. https://doi.org/10.1177/2050157914557691

Waldman, S., and the Working Group on Information Needs of Communities (2011). The information needs of communities. Federal Communications Commission. www.fcc.gov/infoneedsreport

Westlund, O. (2015). News consumption in an age of mobile media: Patterns, people, place, and participation". Mobile Media \& Communication, 3(2), 151-159.

https://doi.org/10.1177/2050157914563369

Xiang, Y., \& Sarvary, M. (2007). News Consumption and Media Bias. Marketing Science, 25(5), 611-628. https://doi.org/10.1287/mksc.1070.0279

\section{AUTORES:}

\section{Juan Pablo Artero}

Doctor en Comunicación y profesor contratado doctor de Periodismo de la Universidad de Zaragoza. Desde marzo de 2018 es vicepresidente del consejo de administración de la Corporación Aragonesa de Radio y Televisión (CARTV).

jpartero@unizar.es 
Índice H: 8 .

Orcid ID: http://orcid.org/0000-0001-9913-2705

Google Scholar: https://scholar.google.com/citations?user=lryLL6AAAAAJ\&hl=en

\section{Víctor Orive}

Doctor en Economía y Organización de Empresas y profesor ayudante doctor en la Escuela Universitaria de Turismo de la Universidad de Zaragoza. Imparte Investigación de mercados y Marketing y calidad de destinos turísticos.

orive@,unizar.es

\section{Índice H: 3.}

Orcid ID: http://orcid.org/0000-0001-6467-7414

Google Scholar: https://scholar.google.com/citations?user=45mYoI0AAAAJ\&hl=en

\section{Pilar Latorre}

Ingeniera industrial, doctora en Economía y Organización de Empresas y profesora ayudante doctora de Organización de Empresas en la Universidad de Zaragoza. Investiga en operaciones, evaluación del desempeño y benchmarking.

latorrep@unizar.es

Índice H: 5.

Orcid ID: http://orcid.org/0000-0002-8486-6885

Google Scholar: $\underline{\text { https://scholar.google.com/citations? user=LCHaQewAAAAJ\&hl=en }}$ 